\title{
Los avatares de un señorío de frontera en la Baja Edad Media. Jódar (Jaén) entre los siglos XIII y XV'
}

\author{
María Antonia Carmona Ruiz ${ }^{2}$
}

Recibido: 28/ de septiembre de 2016 / Aceptado: 14 de diciembre de 2016

\begin{abstract}
Resumen. En este artículo se estudia las vicisitudes que sufrió el señorío de Jódar desde su conquista, caracterizado por el continuo cambio de titularidad entre los siglos XIII y XV, a consecuencia de su condición fronteriza y de la convulsa vida política que vivió la Corona de Castilla durante esas centurias. Hasta que pasó a formar parte del linaje de los Carvajal, la localidad de Jódar perteneció sucesivamente a Sancho Martínez de Jódar, a los Méndez de Sotomayor, a Enrique y Leonor Enríquez, a Juan Alfonso de Guzmán, a Ruy López Dávalos, a Juan de Perea y Beatriz García de Villandrando, a Pedro y Fernando de Zúñiga y finalmente, a Pedro Girón.
\end{abstract}

Palabras clave: señorío; nobleza; Andalucía; reino de Jaén; Castilla; frontera.

\section{[en] The Ups and Downs of a Border Estate in the Middle Ages. Jódar (Jaén) between the $13^{\text {th }}$ and $15^{\text {th }}$ Centuries}

\begin{abstract}
This article discusses the ups and downs endured by the estate of Jodar since the time of its conquest. The estate changed hands on a continual basis between the 13th and 15th centuries due to its border location and the tumultuous political life experienced by the Crown of Castile during those centuries. Up until it became part of the Carvajal bloodline, the town of Jódar belonged successively to Sancho Martínez de Jódar, the Méndez de Sotomayor family, Enrique and Leonor Enríquez, Juan Alfonso de Guzmán, Ruy López Dávalos, Juan de Perea and Beatriz García de Villandrando, Pedro and Fernando de Zúñiga and, finally, to Pedro Girón.
\end{abstract}

Keywords: Estate; Nobility; Andalusia; kingdom of Jaen; Castile; Border.

Sumario: 1. Introducción. 2. La conquista y señorialización de Jódar. 3. El señorío de Sancho Martínez de Jódar. 4. Los herederos de Sancho Martínez de Jódar y el señorío de los Méndez de Sotomayor. 5. Las vicisitudes del señorío de Jódar entre finales del siglo XIV y finales del siglo XV. 6. Conclusiones. 7. Bibliografía.

Cómo citar: Carmona Ruiz, M.A. (2017) Los avatares de un señorío de frontera en la Baja Edad Media. Jódar (Jaén) entre los siglos XIII y XV, en En la España Medieval 40, 163-189.

\footnotetext{
1 Este trabajo forma parte del proyecto de investigación financiado por el Ministerio de Economía y Competitividad y que lleva por título "Poder, fiscalidad y sociedades fronterizas en la Corona de Castilla al sur del Tajo (siglos XIV-XVI)”. (referencia HAR2014-52469-C3-1-P).

2 Universidad de Sevilla mantonia@us.es
} 


\section{Introducción}

Hace ya algunas décadas que se estudia el fenómeno de la señorialización de Andalucía con bastante profundidad ${ }^{3}$. No obstante, y pese a los esfuerzos realizados hasta ahora, estamos aún bastante lejos de llegar al total conocimiento de la geografía señorial andaluza. La proliferación de pequeños señoríos, muchos de ellos localizados en espacios periféricos y pertenecientes a linajes con escasa importancia dentro del panorama político castellano, explican en parte este hecho, considerando además que ha existido una predilección por el estudio de los grandes linajes y sus haciendas, aunque también se debe a la falta de información existente, tanto para el estudio de la baja nobleza andaluza como de los pequeños enclaves señoriales andaluces. Por otro lado, a la hora de analizar las haciendas de los grandes magnates del reino, habitualmente los estudios se limitan a hacer largas enumeraciones de sus tierras y señoríos, sin pararse a examinar el proceso de adquisición de las mismas, por lo que difícilmente podemos acercarnos a la realidad que vivieron esas villas señoriales.

La localidad de Jódar es un caso paradigmático de ello. Un pequeño señorío que surgió tras la conquista cristiana en el siglo XIII en la frontera del reino de Jaén con Granada y que en las dos centurias siguientes experimentó numerosos cambios de titularidad, en parte debido a su condición fronteriza y a las dificultades económicas que se vivieron en los siglos bajomedievales, pero también a consecuencia de la convulsa vida política que vivió la Corona de Castilla entre los siglos XIV y XV, a las dificultades económicas de algunos señores que se vieron obligados a vender sus propiedades y al proceso de fragmentación del patrimonio debido a las herencias.

A la hora de abordar este estudio, nos encontrarnos con una importante falta de información debido a la escasa y dispersa documentación conservada. Consecuencia de ello es que a lo largo de los siglos numerosos autores hayan intentado recomponer su pasado apoyándose principalmente en noticias mal interpretadas o simplemente erróneas que se han ido repitiendo sin base histórica que las corrobore. A esto hay que añadir que en numerosos casos los datos que nos ofrecen son contradictorios, complicando aún más un panorama en el que predominan las hipótesis. La consecuencia es que a la hora de estudiar el devenir histórico del señorío de Jódar están comúnmente aceptadas una serie de premisas, algunas erróneas, que analizaremos a lo largo de este trabajo aportando nuevos datos que completan los conocimientos que tenemos sobre la evolución de este señorío a lo largo de la Baja Edad Media.

\section{La conquista y señorialización de Jódar}

Jódar es una localidad situada al norte de la Sierra Mágina, en el valle del Jandulilla, un camino tradicional y zona de intercambios que comunicaba la hoya de Guadix con el valle del Guadalquivir. Esta circunstancia, junto al hecho de haber sido el escenario de numerosas luchas y enfrentamientos durante la época islámica, explica que en ese periodo fuera un territorio caracterizado por la existencia de una gran

\footnotetext{
No podemos hacer aquí una exhaustiva relación de autores, por lo que nos limitaremos a señalar los últimos estados de la cuestión que se han elaborado para Andalucía. Destacamos: Cabrera Muñoz "Nobleza y señoríos en Andalucía" y "Feudalismo y señoríos en Andalucía", Collantes de Terán Sánchez "Los señoríos andaluces", Ladero Quesada "Sociedad feudal y señoríos en Andalucía", Quintanilla Raso "La sociedad política. La nobleza" y "La nobleza en Andalucía del siglo XV".
} 
abundancia de fortificaciones ${ }^{4}$. Entre las diferentes poblaciones destacaba Sawdar (Jódar), como cabecera de un iqlim. Antes de su conquista por los castellanos en el siglo XIII, formaba parte de las posesiones de un personaje llamado Abd al-Aziz al-Numayri, que también poseía Garcíez (Qarsis), Cuadros (Qutrus) y Bedmar (alManzar) $)^{5}$.

La conquista cristiana de Jódar se produjo durante las campañas que Fernando III efectuó en el alto Guadalquivir, aprovechando la crisis dinástica del imperio almohade provocada tras la muerte en 1224 de Yusuf II sin descendencia, que desembocó en luchas y disensiones entre los miembros de la dinastía aspirantes al trono. Entre ellos, destacamos a Muhammad al-Bayyasi, quien pretendía crearse un principado independiente en al-Andalus y que, ante las dificultades militares que se encontró para sus propósitos, realizó un pacto con Fernando III mediante el cual el monarca castellano se comprometía a ayudarle en sus conquistas a cambio de repartírselas. Entre las plazas que Fernando III recibió se encontraba, muy cerca de Jódar, Garcíez $^{6}$. No obstante, en otoño de 1225 Garcíez fue ocupada por el califa almohade, al-'Adil'.

Sin embargo, esta situación duró poco ya que después de la muerte de al-Bayyasi, y la conquista de Baeza en 1226, la comarca del Jandulilla cayó en manos cristianas mediante capitulaciones ${ }^{8}$, al quedar totalmente desguarnecida y sin protección, lo que permitió la permanencia en la zona un nutrido grupo de mudéjares. Desconocemos la fecha exacta de la conquista de Jódar, pero es muy posible que ésta se llevara a cabo en junio o julio de $1229^{9}$.

A través de la información que nos ofrecen tanto Rodríguez de Rada como $\mathrm{La}$ Primera Crónica General podemos afirmar que la conquista de Jódar se produjo durante la campaña que Fernando III desarrolló tras la toma de Baeza, con el fin de ocupar parte del valle del Jandulilla, vía de comunicación fundamental que conectaba el alto Guadalquivir con Granada. Ambas crónicas nos indican que en una incursión Garcíez, Jódar y Sabiote, coincidiendo en el tiempo con la estancia de Juan de Abberville, cardenal y obispo de Santa Sabina, como legado papa ${ }^{10}$.

Con la conquista de Garcíez y Jódar, Fernando III cerraba el paso a posibles incursiones musulmanas a través de este pasillo, consolidando de este modo la situación de Baeza ${ }^{11}$. Posteriormente se inició la reorganización del territorio conquistado, en el que se concedió a Baeza un Fuero y unos términos propios en los que incluyeron un buen número de villas aldeas dependientes de su jurisdicción, conformando una "comunidad de villa y tierra", a semejanza de las que existían en Castilla. En el sur se establecieron como límites algunos macizos del prebético: la línea de cumbres

$4 \quad$ Vidal Castro, Frontera Sierra Magina, p. 23. Alcalá Moreno, "Los castillos y fortalezas del curso bajo del Río Jandulilla".

5 Vidal Castro, Frontera Sierra Magina, p. 16, Aguirre Sadaba, El Jaén islámico, p. 186. Olmo López, Las subbéticas islámicas, pp. 136-138.

Ibn Abī Zar'. Rawḍ al-Qirțās, vol. 2, p. 524.

Argote de Molina, Nobleza de Andalucía, 138; Quesada Quesada, La Serranía de Mágina, p. 38.

Quesada Quesada, "Los pactos de sumisión de los mudéjares", p. 522.

González. Reinado y Diplomas de Fernando III, vol I, p. 312.

10 Rodrigo Jiménez de Rada, Historia de los hechos de España, p. 344. Primera Crónica General, p. 720.

11 Quesada Quesada, La Serranía de Mágina, p. 39. 
de Sierra Mágina y la sierra de Bedmar y Jódar ${ }^{12}$, quedando fuera del alfoz baezano algunas localidades fronterizas con Granada que pasaron a manos señoriales, entre las que se encontraba la villa de Jódar.

En relación a esto, lo lógico es plantearnos en manos de quién quedó la localidad de Jódar. Aunque varios genealogistas aluden a ello en sus trabajos, sin embargo, nos ofrecen una información muy desigual. Así, el más cercano en el tiempo es el conde de Barcelos, quien en su Livro de Linhagens, haciendo referencia a los señores del Carpio, escribió que Garci Méndez de Sotomayor se casó con una hija de Sancho Pérez, conquistador y señor de Jódar ${ }^{13}$. Sin embargo, considerando que esta obra adolece de importantes errores, creemos que la noticia es poco fiable, teniendo en cuenta además que geográficamente quedaba un poco lejos de los hechos que narra. Por su parte, el genealogista Antonio de Barahona, a finales del siglo XV señalaba que recibió esta localidad un tal don Martín, padre de Sancho Martínez de Jódar, Adelantado de la Frontera ${ }^{14}$. Gonzalo Argote de Molina, por otra parte, nos ofrece una información contradictoria, porque mientras que en un momento escribió que, siguiendo el trabajo del conde de Barcelos, conquistó la villa un caballero llamado Sancho Pérez ${ }^{15}$, sin embargo, más adelante, citando erróneamente la misma fuente, indica que el conquistador de Jódar fue don Sancho Martínez ${ }^{16}$.

En cualquier caso, e independientemente de su conquistador o conquistadores, todos los historiadores coinciden en un hecho: y es el de que en el siglo XIII Jódar pasó a formar parte de un señorío. Y es interesante recalcar este hecho, porque tras la conquista de Andalucía los señoríos nobiliarios que se crearon durante el siglo XIII fueron muy pocos y muy selectivos. Además, generalmente sus beneficiaron eran miembros de la familia real, y fuera de ella, personajes muy destacados del entorno más inmediato del rey o algunos nobles que hicieron méritos relevantes para merecer tal recompensa. Estos últimos no fueron muy numerosos y generalmente consistieron pequeños núcleos de población o plazas de frontera muy difícilmente defendi-

12 1231, mayo 19. Burgos. Archivo Histórico Municipal de Baeza (en Adelante AHMB), 1/1/1. “Así, pues, os doy y concedo términos por los parajes expresados a continuación, a saber, a lo largo del Puerto del Muradal, como discurren las aguas hacia Baeza y como se va por la cima de la Sierra, directamente, hasta donde desemboca el Ferrumbral en el Guadalquivir, y desde Ferrumbral, aguas arriba del Guadalquivir, hasta Torres, tal como limita el término con Jaén: asimismo os doy Torres con su término, y desde allí, caminando por la cima de la Sierra de Bedmar y de Jódar, tal como corren las aguas hasta Baeza y como se desciende de la sierra de Jódar directamente hasta Jandulilla. También os doy el Jandulilla con su término, que abarca hasta el Guadalquivir, y desde allí tal como Baeza separa su término de Úbeda y Vilches con Santisteban y la Torre de Alber, siguiendo directamente hasta la cima de la Sierra del Muradal, desde donde se vuelve al Puerto del Muradal". Trad. J. Rodríguez Molina (Coord.), Historia de Baeza, pp. 123-124. Traduce también el privilegio Argote de Molina. Nobleza de Andalucía, p. 175.

13 "Este Garcia Meendez de Xodar foi casado com dona Johanna Rodriguiz, Filha de dom Sancho Perez, o que gaanhou Xodar aos Mouros, e por este casamento foi este Garcia Meendez senhor de Xodar. E houve este Garcia Meendez de Xodar em esta dona Johanna Rodriguiz, sa molher, filhos". (Afonso, Livro de Linhagens, vol. 1, título XXX, p. 351).

14 "El santo rey don Fernando, tercero deste nombre, ganó la villa de Xódar, la qual dio a un caballero que se decía don Martín. Éste fue padre de Sancho Martínez de Xódar, Adelantado que fue de la frontera [...] A don Martín de Xódar se le dio la villa de Xódar porque se halló en ganalla”. Libro de los linages de Baeza, así ganadores como pobladores de ella, compuesto por D. Antonio de Barahona y aumentado por otros. Biblioteca de la Real Academia de la Historia (en adelante BRAH), 9/194.

15 "Por el libro del conde D. Pedro, título 31, consta haber ganado el castillo de Jódar un caballero llamado D. Sancho Pérez" Argote de Molina, Nobleza de Andalucia, p. 194

16 "como escribe el conde D. Pedro en el título 31 de D. Gomez Gedeon, este caballero ganó de los moros la villa y castillo de Xodar, y por ella usó este apellido..." Argote de Molina, Nobleza de Andalucía, p. 273. 
bles ${ }^{17}$. Es precisamente el caso de Jódar, una localidad periférica, situada en primera línea de frontera, mal poblada y con bastantes dificultades para su salvaguarda, aunque con posibilidades de incrementar sus posesiones a costa del territorio granadino y de aumentar sus beneficios económicos con el asentamiento de nuevos pobladores y el control de las poblaciones mudéjares preexistentes.

De todos los personajes que anteriormente hemos citado como posibles conquistadores de Jódar (Martín de Jódar, Sancho Pérez o Sancho Martínez de Jódar), hay tan sólo uno del que podemos confirmar su pertenencia al círculo del rey y es el caso de Sancho Martínez de Jódar, quien llegó a tener un cargo tan importante como el de Adelantado de la Frontera.

\section{El señorío de Sancho Martínez de Jódar}

Sabemos muy poco del origen familiar de Sancho y, de hecho, tanta dificultad encontró Gonzalo Argote de Molina para reconstruir tanto su Historia como la de su linaje, que le llevó a decir que "aunque con mucha diligencia he procurado saber del linaje de sus antecesores y cuyo hijo fue, no he hallado escrituras con qué certificarlo" 18 .

Quien nos ofrece más información al respecto es Francisco Ruano, que señala que era hijo de Lope Sánchez de Valenzuela y doña Sancha Alfonso de León, hija ésta a su vez de Rodrigo Alfonso de León, bastardo de Alfonso IX ${ }^{19}$. Sin embargo, debemos de ser cautos con esta información, considerando además que la finalidad de esta obra era ensalzar a la familia de los Cabrera y que los datos que nos ofrece no son siempre fiables. De hecho, analizando la Relación de los Trescientos caballeros que poblaron Baeza y Úbeda, publicada por Ximena Jurado $^{20}$, figuran un tal Martín Sánchez de Jódar y a continuación un tal Sancho Martínez, que podría ser su hijo, y por lo tanto Sancho Martínez de Jódar, como han indicado algunos autores, caso del propio Ximena Jurado ${ }^{21}$.

La documentación que se conserva relacionada con Sancho Martínez de Jódar es bastante limitada, pero a partir de ella podemos reconstruir al menos someramente parte de su trayectoria. De hecho, sabemos que participó desde los primeros momentos en la conquista de Andalucía al servicio de Fernando III. Incluso, es muy probable que interviniera en la ocupación de Baeza y Úbeda, como se puede deducir de su presencia en la citada nómina de los Trescientos caballe$\operatorname{ros}^{22}$. Son muchos los problemas que plantea esta nómina de repobladores, al ser muy tardía y tratarse conjuntamente lugares conquistados en fechas distintas ${ }^{23}$, pero es muy posible que, aunque sufriera interpolaciones posteriores, algunos nombres fueran ciertos, como posiblemente sea el caso de Sancho Martínez de

\footnotetext{
17 Cabrera Muñoz, "La señorialización de Andalucía", pp. 71-75. Cabrera Muñoz, "Repoblación y señoríos", pp. 1118-1120

18 Argote de Molina, Nobleza de Andalucía, p. 273.

19 Ruano, Historia de la Casa de Cabrera en Córdoba, p. 389

20 Ximena Jurado, Catálogo de los obispos, pp. 119-122.

21 Así, al margen de la transcripción que hace del documento de donación de los castillos de Chincóyar y Ablir al concejo de Baeza de 1243, que se debería hacer efectiva a la muerte de Sancho Martínez de Jódar, Ximena Jurado indica que éste "Es uno de los Trecientos infançones”. Ximena Jurado, Catálogo de los obispos, p. 143.

22 Ximena Jurado, Catálogo de los obispos, pp. 119-122.

23 González Jiménez, "Baeza después de la conquista", p. 35.
} 
Jódar, quien a consecuencia de su participación en la conquista debió de ser uno de los beneficiarios de tierras ${ }^{24}$.

Las intervenciones militares de Sancho Martínez de Jódar continuaron en la conquista andaluza junto con Fernando III, protagonizando incluso una entrada en la vega de Granada en 1244 junto a don Alfonso de Molina, hermano de Fernando III, a la que se sumaría el propio rey, arrasando durante veinte días los alrededores de Granada ${ }^{25}$. Que en la Primera Crónica General se mencionara a Sancho Martínez de Jódar junto a los contingentes de los grandes concejos del Alto Guadalquivir muestra que debió de ser una persona muy valiosa desde el punto de vista militar.

A consecuencia de ello debió de ser recompensado con numerosas propiedades, aunque se conserva información tan sólo de algunas de ellas. Así, en fecha desconocida Sancho Martínez de Jódar obtuvo la tenencia de las fortalezas de Chincóyar y Neblir. Es muy probable que interviniera directamente en su conquista, hacia 1227, de ahí que las recibiera de forma vitalicia. Esto lo sabemos a partir de un documento de 1243 en que Fernando III concedía a Baeza estos castillos, aunque sólo se haría efectiva la donación tras la muerte de Sancho Martínez ${ }^{26}$. No obstante, el privilegio al concejo baezano no se llevó a cabo, ya que en 1260 Alfonso X concedió estos castillos junto con el de Cuadros al obispo de Jaén, con la condición, igualmente, de que los mantuviera Sancho Martínez de Jódar hasta su muerte ${ }^{27}$. Del mismo modo, la donación al obispado tampoco se hizo efectiva, ya que en 1276 Alfonso X los otorgaba a un tal don Bretón ${ }^{28}$. Es posible que la donación a Sancho Martínez de Jódar fuera consecuencia de que consiguiera establecer un pacto con las aljamas de estas comunidades, situadas en una zona que posiblemente no hubieran estado controladas por al-Bayasi, y que la entrega a Sancho Martínez de Jódar hubiera sido una fórmula intermedia antes de la entrega definitiva a Baeza ${ }^{29}$.

Desconocemos la fecha en que Sancho Martínez se convirtió en señor de Jódar, pero suponemos que debió de ser pronto, bien sucediendo a su posible padre, el citado Martín Sánchez de Jódar, bien recibiéndolo directamente del rey. De hecho, tanto él como su padre podrían haberla recibido a consecuencia de los méritos demostrados en su conquista, algo habitual en la época ${ }^{30}$. Lo que sí sabemos es que en 1255 en una avenencia que firmó con el obispo de Jaén se intitulaba "señor de Xódar" Además, a través de otro acuerdo realizado con el obispado, sabemos que llegó a poseer otros lugares cercanos, como los poblados de Solera, Polera, Gris, Alló y Odgáyar $^{32}$, alquerías próximas a las fortalezas de Chincóyar y Neblir, que estaban pobladas por musulmanes.

Ibid. 36.

Primera Crónica General, cap. 1063, p. 743.

6 1243, abril, 6. Valladolid. En este privilegio Fernando III concede al concejo de Baeza además de los castillos de Chincóyar y Ablir, los de Vilches, Baños y la torre de Estiviel, comprometiéndose a entregarle Huelma y Bélmez cuando se conquistaran. AMB, 1/1/2. Edit. Rodríguez Molina. Colección documental del Archivo Municipal de Baeza, doc. 3 y González, Reinado y diplomas de Fernando III, vol. III, doc. 708.

7 1260, julio, 6. Córdoba. Edit. González Jiménez, Diplomatario, doc. 229.

1276, julio, 14. Burgos. Edit. González Jiménez, Diplomatario, doc. 429.

Quesada Quesada, "Formas de poblamiento en un área rural de al-Andalus”, pp. 15-16.

González, Reinado y diplomas de Fernando III, tomo I, p. 128.

1255, agosto, 18. Jaén. Edit. Segura Moreno. Estudio del Códice Gótico, p. 191. (doc. 9 de los romances).

1255, agosto, 18. Jaén. Edit. Segura Moreno, Estudio del Códice Gótico, pp. 192-193. (doc. 10 de los romances). 
Asimismo, amplió sus dominios en la zona con la torre y el cortijo de Garcíez, que le concedió en 1269 Alfonso X tras comprárselo a Baeza ${ }^{33}$. Esta donación se debió a sus servicios militares en la frontera, destacando posiblemente su ayuda prestada a los Ashqilula ${ }^{34}$. No obstante, el concejo baezano fue bastante reticente a entregarla, pero obligado por el monarca la cedió finalmente en $1273^{35}$, poco antes del fallecimiento de Sancho Martínez. La tenencia de este señorío suponía, el control y disfrute de las propiedades y rentas de las villas que los integraban, así como de la jurisdicción sobre toda su población.

Tuvo también propiedades en otras localidades jienenses, de las cuales conocemos una parte, como una casa entre Rus y Canena, que donó al obispo de Jaén tras su muerte ${ }^{36}$. Asimismo, en 1255 reconocía que cobraba de forma vitalicia numerosos diezmos de las tierras que tenía en el obispado, así como de localidades cercanas, caso de Jimena y Garcíez, algo que en principio pertenecía al obispo pero que él percibía, comprometiéndose a devolverle ese derecho cuando muriera, prometiéndole además, y como contraprestación, que si él o sus descendientes ganaban alguna plaza a los moros darían la tenencia de su iglesia al prelado jiennense ${ }^{37}$. Con estas palabras Sancho Martínez de Jódar nos presenta unas de las razones por las que los reyes entregaban señoríos en la frontera: además de asegurar la defensa de las plazas ganadas, consolidar una población y promover la expansión a costa del territorio granadino.

Consolidado como un importante señor, su participación en las empresas militares de Fernando III continuaría, y a consecuencia de ello fue recompensado tras la conquista de Sevilla, que se produjo en 1248. De hecho, en el Repartimiento de Sevilla recibió un importante heredamiento con propiedades en los lugares de Pilas y Huévar ${ }^{38}$. Y, aunque no tenemos datos ya que no se conservan los libros de repartimiento, es muy posible que también fuera recompensado en otros territorios andaluces.

Aparte de estos lugares, de los que tenemos constancia documental que pertenecieron a Sancho Martínez de Jódar, autores posteriores afirmaron que fue señor también de otras localidades como El Carpio, Bedmar o incluso Jimena y Albanchez.

Con respecto a El Carpio, fue Argote de Molina el que afirmó que esta localidad perteneció a Sancho Martínez de Jódar, dato que se ha ido repitiendo sin ninguna constancia documental. Sin embargo, y como veremos en el siguiente apartado, donde se trata el tema con detenimiento, lo que pudo poseer, si acaso, fue algún tipo de heredamiento.

Tampoco está muy claro si Sancho Martínez fue o no señor de Bedmar. La idea de que esta localidad perteneció a Sancho Martínez de Jódar procede también de Gonzalo Argote de Molina, quien lo consideró señor de esta villa ${ }^{39}$ y que ha sido repetida igualmente en numerosas ocasiones ${ }^{40}$, aunque no conservamos ninguna documen-

\footnotetext{
1269, marzo, 18. Jaén. González Jiménez, Diplomatario andaluz Alfonso X, doc. 360.

Ballesteros Beretta. Alfonso X, p. 478.

35 1273, abril, 21. Ávila. González Jiménez, Diplomatario, doc. 401. Alfonso X ordenaba a Gil Pérez y a Pedro Ruiz, jurados del rey en Baeza, que entreguen a Sancho Martínez de Jódar la Torre del castillo de Garcíez. Esta donación se hizo efectiva al 10 de octubre de 1273. Edit. Don Lope de Sosa, no 98, febrero 1921, p. 60.

36 1274, enero, 9, Jódar. Edit. Segura Moreno, Estudio del Códice Gótico, p. 211. (doc. 23 de los romances).

37 1255, agosto, 18, Jaén. Edit. Segura Moreno, Estudio del Códice Gótico, p. 191. (doc. 9 de los romances).

38 Vázquez Campos, Los adelantados mayores de la frontera, pp. 89-90.

39 Argote de Molina, Nobleza de Andalucía, pp. 273-274.

40 Rodríguez Molina, El reino de Jaén en la Baja Edad Media, p. 72; Quesada Quesada, La Serranía de Mágina, p.
} 
tación que corrobore esta afirmación. Antonio de Barahona por el contrario consideraba que el primer señor de la villa de Bedmar fue un tal don Martín Sánchez de Bedmar, del que descendía el caballero que la perdió en época de Fernando IV, que se llamaba Sancho o Alonso Sánchez de Bedmar ${ }^{41}$. El nombre de Martín Sánchez de Bedmar aparece también en la controvertida relación de los Trescientos caballeros que poblaron Baeza y Úbeda ${ }^{42}$. Por su parte, Tomás Quesada planteaba como hipótesis que el tal Sancho Sánchez de Bedmar podría haber sido hijo de Sancho Martínez de Jódar y que se hubiera cambiado el apellido al heredar de su padre la localidad de Bedmar $^{43}$, lo que creemos bastante improbable.

Asimismo, Tomás Quesada supuso que Albanchez debió pertenecer a Sancho Martínez ya que en 1338 un tal Ruy Fernández de Xódar, que podría haber sido su descendiente, la vendió a Alfonso XI, para posteriormente éste donarla a Úbeda ${ }^{44}$. Sobre Jimena, lo planteó como hipótesis, pero sin establecer ningún argumento ${ }^{45}$.

Debemos destacar también la actuación de Sancho Martínez de Jódar como Adelantado de la Frontera. Fue el rey Alfonso X quien lo nombró para tal oficio en junio de 1253, estando precisamente en Sevilla realizando su repartimiento. Mantuvo este cargo cinco años, hasta 1258 , fecha en que fue sustituido ${ }^{46}$, aunque ello no significó en absoluto que perdiera el favor del rey, como lo demuestra la citada donación del castillo de Garcíez. Su vida a partir de ese momento estaría vinculada a su actuación militar y a la gestión del señorío.

Y en relación a la gestión del señorío, tampoco sabemos mucho. Por su localización fronteriza era una zona de inseguridad permanente, donde además, tras la conquista se mantuvo una comunidad mudéjar que se quedó en el territorio en virtud de las capitulaciones que debió firmar Fernando III. Conocemos la existencia de población mudéjar a partir de un documento de avenencia firmado en 1255 entre el obispo de Jaén y Sancho Martínez de Jódar en el que este último reconocía cobrar de forma vitalicia el diezmo de los moros de los lugares de Jódar, Garcíez, Jimena y de los lugares que poseía ${ }^{47}$, que serían las citadas alquerías de Solera, Polera, Gris, Alló

95, Troyano Biedma, "La villa de Bedmar", 2001, p. 61. Como argumento para afirmar que Bedmar perteneció a Sancho Martínez de Jódar Tomás Quesada piensa que posiblemente lo heredara un hijo que se cambiaría el nombre por el de Sancho Sánchez de Bedmar.

41 "Ansí mismo por esta vía y manera se dio la villa de Bedmar a don Martín Sánchez de Bedmar, de la qual dicha villa renonbró Bedmar él y todos sus desçendientes. Vn señor desta villa fue preso y cativo, a cuya causa perdieron la posesión de la dicha villa, y el cuarto rey don Fernando el çitado la tornó a ganar y se la dio a la orden de Santiago". Libro de los linages de Baeza, así ganadores como pobladores de ella, compuesto por D. Antonio de Barahona y aumentado por otros. BRAH, 9/194. Según la Crónica de Fernando IV, el caballero que la perdió en 1302 era Sancho Sánchez de Bedmar, cuya mujer, Mari Jiménez, y sus hijos, Juan Sánchez y Jimén Pérez cayeron presos. Crónica de Fernando IV, p. 125. Por otro lado, en un documento de 1295, en que se establece la hermandad entre los concejos del reino de Jaén y varios nobles de la zona en defensa del rey Fernando IV, aparecen como firmantes “Juan Sánchez y Simón Pérez, hijos de Alonso Sánchez, señor de Bedmar'. Este documento original, conservado en el Archivo Municipal de Úbeda muestra que la crónica se equivoca en el nombre del señor de Bedmar, quien era Alonso y no Sancho. 1295, septiembre, 8. Andújar. AMU, carp. 4, nº 14. Edit. Rodriguez Molina, Colección documental del Archivo Municipal de Úbeda, doc. 68.

42 Ximena Jurado, Catálogo de los obispos, p. 120.

43 Quesada Quesada, La Serranía de Mágina, p. 96.

44 Tomás Quesada plantea como hipótesis que Jimén Pérez hubiera sido señor de Albanchez y fuera hijo de Sancho Sánchez de Bedmar, y éste a su vez hijo de Sancho Martínez de Jódar. Por su parte Jimén Pérez sería ascendiente a su vez de Ruy Fernández de Jódar. Quesada Quesada, La Serranía de Mágina, p. 100 y 113.

$45 \quad$ Ibid. p. 99.

46 Un estudio pormenorizado sobre su actuación como adelantado en Vázquez Campos. Los adelantados mayores de la Frontera, pp. 86-95.

47 1255, agosto, 18. Jaén. Edit. Segura Moreno, M. Estudio del Códice Gótico de la catedral de Jaén, p. 191. (doc. 9 de los romances). 
y Odgáyar, posiblemente organizadas en torno a los castillos de Chincóyar y Ablir. La importancia económica de esta comunidad puede explicar el interés de Sancho Martínez de Jódar por obtener el diezmo de los moros de las poblaciones tanto de su señorío como de localidades cercanas. Además, percibía el diezmo del almojarifazgo de sus propiedades ${ }^{48}$, junto con dos tercios del diezmo de los vecinos de los lugares de Solera, Polera, Gris, Alló y Odgáyar ${ }^{49}$.

En estas circunstancias la función de Sancho Martínez de Jódar era principalmente defender el territorio frente a posibles incursiones granadinas, vigilar a la población musulmana que permanecía en la zona ante el temor de acciones violentas y facilitar la llegada de nuevos pobladores cristianos, que, aunque debieron ser pocos, se asentaron allí desde el primer momento, creando un incipiente concejo. A cambio, él conseguía rentas inherentes a su condición de señor, además de algunas que pertenecían a la Iglesia y que él mismo había usurpado. En todo ello la existencia de una fortaleza era esencial, tanto por su función militar, como administrativa, convirtiéndose la antigua alcazaba de Jódar en el edificio fundamental de la villa, adaptándose a las nuevas exigencias. Así, se debió acondicionar para que pudiera albergar a un número importante de guerreros que eran garantía de seguridad para la población cristiana que habitaba la localidad ${ }^{50}$. Además, se convirtió en el centro de una red de castillos y torres vigías, en la que tomaban parte además los castillos de Chincóyar, Ablir, Cuadros y Albanchez.

Pero la situación cambió radicalmente a partir de 1264 . Y es que en esa fecha debido al incumplimiento de los pactos por los cristianos y a la cada vez mayor presión fiscal sobre los mudéjares, se produjo una sublevación generalizada de la población musulmana de Andalucía y Murcia y el ataque simultáneo de los granadinos en los puntos más avanzados de la frontera. La reacción cristiana fue muy violenta, y en el caso del Alto Guadalquivir, en la primavera de1265 los principales concejos de los reinos de Jaén y Córdoba junto con Día Sánchez de Funes y Sancho Martínez de Jódar firmaron un acuerdo de "hermandad" para apoyarse mutuamente contra los $\operatorname{moros}^{51}$. Que Sancho Martínez y Día Sánchez, que fueron adelantados de la frontera, efectuaran una alianza de igual a igual con los concejos da una idea de su poder en la región.

La revuelta fue finalmente sofocada por las tropas castellanas, y la consecuencia principal fue la expulsión de buena parte de la población mudéjar de Andalucía, afectando especialmente a las comarcas donde eran muy numerosa, como posiblemente era el caso del señorío de Sancho Martínez de Jódar. Y, de hecho, la desaparición de la población mudéjar en la zona debió de perjudicarle notablemente debido a la escasez de población cristiana que debía de haber en ese momento. Esto puede explicar que, con la intención de organizar el concejo y promover su repoblación, Jódar recibiera de Alfonso X en 1272 un fuero, que según el documento de concesión, era el fuero de Lorca ${ }^{52}$. Considerando que este privilegio real se concedió a un territorio de señorío, es posible que se otorgara a instancia del propio Sancho Martínez de Jódar, o del mismo concejo galduriense, ante las dificultades que tenían para su repoblación.

\footnotetext{
$48 \quad I d$.

49 1255, agosto, 18. Jaén. Edit. Segura Moreno, M. Estudio del Códice Gótico de la catedral de Jaén, pp. 192-193. (doc. 10 de los romances).

50 Un estudio sobre el Castillo de Jódar es el de Alcalá Moreno, Historia del castillo de Jódar.

51 1265, abril, 26. Andújar. Ed. Memorial Histórico Español, vol. 1, doc. CI, pp. 221-223.

52 1272, abril, 12. Murcia. Ed. González Jiménez, Diplomatario andaluz, doc. 394.
} 
Este documento se expidió el mismo día que otro casi similar en beneficio de los pobladores del alcázar de $\mathrm{Baeza}^{53}$, con la diferencia principal entre ambos que mientras en el primer caso lo que se pretendía era poblar el lugar, en el segundo lo que se trataba era fundar un cuerpo de 33 caballeros con residencia en el alcázar baezano. Debemos de recalcar que las disposiciones incluidas en ambos privilegios proceden del fuero de $\mathrm{Cuenca}^{54}$, por lo que se podría pensar que es un error de la cancillería real al indicar que se le concedía el fuero de Lorca, considerando además que el fuero lorquino procede del de Córdoba y es de la misma familia del de Jaén, que por lógica es el que se debía haber otorgado. Ante esta disyuntiva Pedro Porras propone que en el texto de Jódar, considerando que también tiene similitudes con los fueros de la familia del de Córdoba, se pretendían aunar ambas tradiciones ${ }^{55}$.

Este texto legislativo se divide en 8 disposiciones que estipulaban principalmente la libre disposición de sus propiedades e importantes exenciones fiscales. Sin embargo, estas medidas no fueron suficientes para conseguir que Jódar fuera atractiva a nuevos pobladores, de ahí que en 1286 Sancho IV aumentara los privilegios fiscales de sus vecinos con la exención del pago de moneda forera y de servicio de ganado ${ }^{56}$, privilegios que fueron confirmados por sus sucesores, sin conseguir tampoco con ello una cantidad de población razonable ${ }^{57}$. La peligrosidad de la frontera fue una realidad constante hasta la conquista de Granada, y las dificultades para mantener una población estable eran notables. Los frecuentes robos y cautiverios ${ }^{58}$, las muertes, los incendios de cosechas en ambos lados de la frontera era un hecho manifiesto, pero al mismo tiempo podía proporcionar oportunidades para mejorar las condiciones de vida. La posibilidad de obtener tierras en propiedad, la exención de impuestos y la perspectiva de conseguir botín gracias a las expediciones de rapto y saqueo que periódicamente se hacían en ambos lados de la frontera, eran atractivos importantes pero no suficientes para que el volumen de población fuera aceptable.

Pero si la frontera con Granada era una zona especialmente peligrosa, ésta fue extrema a partir de 1275 , momento en que se iniciaron los ataques de los benimerines, quienes, hasta prácticamente mediados del siglo XIV, asolaron el territorio andaluz junto a los granadinos. Penetraron en la Península Ibérica ante la petición de ayuda del rey de Granada, Muhammad II, iniciando una serie de ataques rápidos de saqueo y destrucción por toda Andalucía, afectando especialmente a las poblaciones de frontera y en concreto al valle del Jandulilla, al conquistar Huelma, Solera y Bélmez, además de arrasar otras localidades y castillos, entre los cuales se encontraban los castillos de Chincóyar y Ablir y las aldeas de Polera, Ogáyar, Gris y Alló, pertenecientes a Sancho Martínez de Jódar y que quedaron a partir de entonces despobladas ${ }^{59}$.

Los ataques benimerines coincidieron con el fallecimiento de Sancho Martínez de Jódar, lo que ha llevado a Tomás Quesada a plantear la hipótesis de que éste pudo

1272, abril, 12. Murcia. Ed. González Jiménez, Diplomatario andaluz, doc. 393.

Vid. Las concordancias en Porras Arboledas, "Fueros, privilegios y ordenanzas de la villa de Jódar", p. 394.

Ibid. pp. 399-400.

1286, noviembre, 14, Valladolid. Edit. Porras Arboledas. "La organización militar y social”, pp. 492-493.

Porras Arboledas. "Fueros, privilegios y ordenanzas de la villa de Jódar" p. 400.

58 En relación con el problema del cautiverio contamos con la narración que Pedro Marín hizo de las vicisitudes que sufrió un galdurienese, Domingo Pérez de Jódar, hasta que finalmente llegó al monasterio de Santo Domingo de Silos. Vid. González Jiménez. Los milagros romanzados, milagro 52, pp. 113-114.

59 Quesada Quesada, La Serranía de Mágina, pp. 50 y ss. 
producirse luchando contra ellos ${ }^{60}$. Desconocemos la fecha exacta de su muerte, aunque debió de producirse antes del 14 de julio de 1276, fecha en que Alfonso X concedía los castillos de Chincóyar y Ablir a un tal don Bretón, indicando expresamente que estas fortalezas habían pertenecido en vida a Sancho Martínez de Jódar ${ }^{61}$. Por otro lado, se conserva la copia de un documento fechado en enero de 1274 en que Sancho Martínez donaba al obispado de Jaén una propiedad que tenía entre Rus y Canena, a cambio de que tras su muerte hiciera tres aniversarios anuales y que tuviera siempre encendida una lámpara en la catedral de Baeza ${ }^{62}$. Claramente en esa fecha Sancho Martínez estaba haciendo ya disposiciones testamentarias, lo que puede indicar que se debía encontrar enfermo. Sin embargo, hay un problema con el año de este documento ya que se conserva la copia de otro documento, fechado en marzo de 1273, en que el obispo de Jaén, don Pascual, asignaba al cabildo catedralicio 100 maravedís de la mesa episcopal para que se dijeran los aniversarios por el alma de don Sancho Martínez, a cambio del heredamiento que tenía en Rus y le donó ${ }^{63}$. Como fácilmente se puede observar al menos una de las dos fechas está equivocada, posiblemente el año 1273, por lo que, si consideramos como válido el mes de marzo de este documento, el fallecimiento de Sancho Martínez de Jódar se pudo producir después de enero de 1274, y antes de marzo de 1276.

La muerte de Sancho Martínez de Jódar coincidió con la descomposición de su señorío, en parte debido a que parte del mismo lo tenía tan sólo de forma vitalicia, caso de Chincóyar y Ablir que, además, como hemos visto, habían caído en manos de los musulmanes, como otras de sus propiedades, caso de Solera, Polera, Gris, Alló y Odgáyar. El resto de sus propiedades se debieron dividir entre sus descendientes, de los que, desgraciadamente, tenemos muy poca información.

\section{Los herederos de Sancho Martínez de Jódar y el señorío de los Méndez de Sotomayor}

Tenemos bastantes dificultades para dilucidar quiénes fueron los descendientes de Sancho Martínez y si realmente heredaron algo. De hecho, apenas contamos con referencias relacionadas con todo este problema lo que ha llevado a numerosos historiadores a jugar con las hipótesis sin argumentos. Entre esa escasa información, se conservan tres documentos relacionados con la guerra civil entre Alfonso X y su hijo Sancho fechados en el 10 de mayo de 1282, en los que se establecieron varios acuerdos entre los concejos de Córdoba, Baeza, Arjona, Úbeda, Santisteban del Puerto y algunos nobles por los que se declaraban vasallos del infante don Sancho, obligándose a defenderse mutuamente ${ }^{64}$. Entre los señores firmantes estaban Sancho

\footnotetext{
$60 \quad$ Ibid, p. 105.

${ }_{61}$ 1276, julio, 14. Burgos. Edit. González Jiménez, Diplomatario, doc. nº 429.

${ }_{62}$ 1274, enero 9. Jódar. Edit. Segura Moreno, Estudio del Códice Gótico de la catedral de Jaén, p. 211. (doc. 23 de los romances).

${ }_{63}$ 1273, marzo 11. El Viso. Edit. Segura Moreno, Estudio del Códice Gótico de la catedral de Jaén, p. 210. (doc. 22 de los romances).

64 1282, mayo 10. S.l. Hermanamiento entre los Concejos de Córdoba, Jaén, Baena, Úbeda, Andújar, Arjona, San Esteban y los señores Gonzalo Ibáñez de Aguilar, Sancho Sánchez y Sancho Pérez de Jódar, por el que se reconocen vasallos del Infante D. Sancho y se obligan mutuamente a defender sus privilegios y a ayudarse en las contiendas. Archivo Municipal de Córdoba (en adelante AMC), carp. 9, perg. 20. 1282, mayo 10. S.1. Hermanamiento entre los Concejos de Córdoba, Jaén, Baeza, Úbeda, Andújar, Arjona, San
} 
Sánchez, fijo de don Sancho Martínez de Jódar, y un tal Sancho Pérez de Jódar, que según se indica en uno de estos documentos era sobrino de Sancho Sánchez ${ }^{65}$, lo que viene a demostrar que Sancho Martínez de Jódar tuvo varios hijos.

Estos documentos se firmaron poco después de la Asamblea de Valladolid (que se celebró el 20 de abril de 1282) en que se desposeyó a Alfonso X de todos sus poderes y rentas, traspasándoselos a su hijo Sancho, acción que fue apoyada por numerosos concejos y nobles ${ }^{66}$. La reacción subsiguiente del rey en la que mostraba su autoridad desheredando a su hijo, fue un importante revulsivo que supuso que muchos de los nobles rebeldes empezaran a volver a la obediencia de Alfonso X durante el año siguiente ${ }^{67}$. Y en medio de esta situación tenemos un documento bastante controvertido, como es la donación que el infante don Sancho hizo en agosto de 1283 al concejo de Baeza de la villa de Jódar ${ }^{68}$. La razón de esta donación la da el propio infante "por muchos serviçios que me fiçieron e me fazen e me farán cabaldelante". Como se puede, se le da en agradecimiento por su fidelidad en la guerra contra su padre, y lo hace a costa de una villa señorial como es Jódar, que en principio podría pertenecer a uno de los firmantes del pacto de 1282. ¿Qué pasó después? Es posible que el señor de Jódar, quizás Sancho Sánchez o Sancho Pérez de Jódar, hubiera dejado la coalición y como represalia, el infante le quitara el señorío. Pero también, algo más simple, que el señor de Jódar hubiera muerto sin descendencia directa y el infante hubiera aprovechado las circunstancias para recompensar a Baeza. Aunque es posible también que el heredero de Jódar no fuera ninguno de estos dos nobles, sino otro hijo, o quizás una hija, Juana Rodríguez de Jódar, casada con el señor de El Carpio, y que simplemente la intentara despojar del señorío para premiar la ayuda que obtuvo de Baeza. En cualquier caso, no debemos olvidar que otra de las propiedades de Sancho Martínez de Jódar, la localidad de Garcíez, dejó de estar en manos de los descendientes de Sancho Martínez ya que, de hecho, pasó a manos de D. Ruy Pérez Ponce, maestre de Calatrava ${ }^{69}$. Al fallecer este último sin descendencia ${ }^{70}$, le sucedió en su posesión su hermano Pedro Ponce de Cabrera, comendador de la orden de Santiago ${ }^{71}$, quien la dividió entre sus hijos Juan Ponce y Toda Pérez Roldán, llevando esta última su parte como dote al matrimonio con Pedro Díaz de Toledo ${ }^{72}$,

Esteban y los señores Gonzalo Ibáñez de Aguilar, Sancho Sánchez y Sancho Pérez de Jódar, para guardarse sus castillos. AMC, carp. 12, perg. 29.

1282, mayo, 10. Carta de poder a Nuño Fernández y a García Pérez, alcaldes y vecinos de Arjona, para hermanarse con los caballeros y hombres buenos de Jaén, y con los señores Gonzalo Ibáñez de Aguilar, Sancho Sánchez y Sancho Pérez. Archivo Municipal de Córdoba, carp. 12, perg. 21. Estos documentos fueron editados en Colección de Documentos Inéditos para la Historia de España (en adelante CODOIN), tomo CXII, Madrid, 1895, pp. 3-6.

65 Archivo Municipal de Córdoba, carp. 12, perg. 21. Edit. CODOIN, CXII, pp. 5-6. Esto desmonta la hipótesis que Tomás Quesada planteó, que suponía que Sancho Pérez de Jódar podría ser el hijo de Sancho Martínez de Jódar y heredero de la villa galduriense y que Sancho Sánchez sería otro hijo que se habría cambiado el apellido a Sancho Sánchez de Bedmar al heredar esa localidad. Quesada Quesada, La Serranía de Mágina, pp. 96 y 106.

66 González, Alfonso X, pp. 345 y ss.

67 Ibid. 355-356.

68 1283, agosto 26. Logroño. Edit. Rodríguez Molina. Colección documental del Archivo Municipal de Baeza, doc. 11

69 Ruano, Casa de Cabrera en Córdoba, p. 111.

70 Afonso, Livro dos linhagens, vol. II/2, Tít. LVIII, F (de E5), p. 100.

71 Ruy Pérez Ponce fue el decimoquinto maestre de Calatrava, cargo para el que fue elegido en 1284. Rades y Andrada, Crónica de las tres Órdenes, fols. 46v-48. Pedro Ponce fue comendador mayor de Castilla de la orden de Santiago, siendo maestre Pelay Pérez Correa, y fue el fundador de la Casa de Cabrera de Córdoba. Ruano, Casa de Cabrera en Córdoba, op. cit. pp. 111-115. Moxó, S. de "De la nobleza vieja a la nobleza nueva", p. 125.

72 Ruano, Casa de Cabrera en Córdoba, op. cit. p. 113. 
quien finalmente conseguiría hacerse con la otra mitad de la localidad ${ }^{73}$.

La donación de Jódar al concejo baezano no llegó a tener mayor transcendencia, y no parece que Baeza llegara a tomar posesión de esta localidad, como demuestra el hecho de que no fuera confirmada por don Sancho cuando se convirtió en rey y que éste en cambio confirmara su fuero en 1286. Desgraciadamente, en este documento no se indica en ningún momento la titularidad de Jódar, aunque muestra el deseo de incrementar la población aumentando sus privilegios fiscales con la exención del pago de moneda forera y de servicio de ganado ${ }^{74}$, lo que nos impide saber en manos de quién estaba la villa. Por otro lado, podemos suponer que los acontecimientos vividos en los últimos años debieron perjudicar notablemente su poblamiento, de ahí que Sancho IV decidiera aumentar sus privilegios.

Ante la falta de documentación directa sobre la titularidad de la villa, tan sólo podemos echar mano de la información que Gonzalo Argote de Molina nos da al respecto, quien explica que Sancho Martínez de Jódar "Dejó una hija heredera de su estado llamada doña Juana Rodríguez de Xódar. Doña Juana Rodríguez de Xódar, señora de Xódar, Bedmar y El Carpio casó con Garci Mendez de Sotomayor, que por este casamiento fue señor de este estado"75. Estos datos, como se puede ver fácilmente se contradicen con los que nos aporta la documentación analizada. En primer lugar, porque Sancho Martínez tuvo más hijos, según hemos visto. En segundo, porque, como ya hemos indicado, parece que el señor de Bedmar fue otro, Sancho o Alonso Sánchez de Bedmar, y además esta villa fue conquistada por los nazaríes en 1302, quienes se llevaron presos a sus hijos Juan Sánchez y Jimén Pérez, desapareciendo de esta forma la familia que había tenido esa localidad. Además, cuando volvió a poder cristiano en 1309, posiblemente Fernando IV la donó a la orden de Santiago ${ }^{76}$, por lo que la localidad de Bedmar no formó parte del señorío de los Méndez de Sotomayor, como veremos a continuación.

Por su parte, Francisco Ruano nos indica que Sancho Martínez se casó con Berenguela de Cabrera y fueron sus hijos Sancho Sánchez de Jódar, identificándolo con el firmante de la hermandad de 1282, Juana Ruiz de Jódar, mujer de Garci Méndez de Sotomayor, señor de El Carpio, y Teresa Martínez de Jódar ${ }^{77}$. Ambos coinciden en el matrimonio del señor de El Carpio con una hija de Sancho Martínez de Jódar, llamada Juana Ruiz o Rodríguez, y que a partir de ahí la villa de Jódar pasó a manos de Garci Méndez de Sotomayor. Lo que no comparten, sin embargo, y como hemos visto, es que El Carpio hubiera pertenecido al adelantado de Andalucía.

El Carpio es una población situada a $30 \mathrm{Km}$. de Córdoba que, como hemos indicado, Argote de Molina consideró que perteneció a Sancho Martínez de Jódar, referencia que se ha ido repitiendo sin ninguna constancia documental ${ }^{78}$. Francisco Ruano por su parte negó rotundamente esta información ${ }^{79}$ y afirmó que Garci Mén-

\footnotetext{
Carmona Ruiz. "En torno al origen de los señoríos del reino de Jaén".

1286, noviembre, 14, Valladolid. Edit. Porras Arboledas, "La organización militar y social”, pp. 492-493.

Argote de Molina, Nobleza de Andalucía, 274.

76 Quesada Quesada, La Serranía de Mágina, p. 113. De hecho, en una Bula de Comisión dada en Avignon en junio de 1313 por el Papa Clemente V, se precisó la libranza de 200.000 maravedís para el fortalecimiento defensivo de las encomiendas de la Orden de Santiago en la Frontera granadina: "Estepa, de Benameji, de Bedmar, ..., de Cuadros, de Chausin, de Veniamarta -Peñamarta-, de Segura, ...". Cfr. Troyano Biedma "La villa de Bedmar", p. 65 .

77 Ruano, La Casa de Cabrera, p. 389

78 Rodríguez Molina, El reino de Jaén en la Baja Edad Media, p. 71.

79 Así dice "el Conde de Lanzarote atribuyó el Señorío del Carpio al Adelantado su suegro [refiriéndose a Garci
} 
dez de Sotomayor había heredado de su familia un donadío que le había entregado Fernando III, situado en un lugar denominado Alcocer, cercana a El Carpio, y que en 1325 reedificó la fortaleza de este último lugar trasladando allí a la población de la vecina Alcocer. Aporta como justificación una lápida fundacional colocada en la fortaleza, en que se indicaba que Garci Méndez de Sotomayor fue señor de Jódar ${ }^{80}$, y a la que haremos referencia de nuevo más adelante.

El problema es ¿a quién pertenecía El Carpio, a Garci Méndez?, o ¿lo usurpó a partir de sus propiedades cercanas del heredamiento de Alcocer, aprovechando que ese lugar se había vaciado y contaba tan sólo de una torre derruida? o quizás ¿eran tierras de Sancho Martínez y que Garci Méndez obtuvo por su matrimonio con su hija, Juana Rodríguez de Jódar, repoblándolas posteriormente? Respecto a la posible usurpación, no es descabellada esta idea ya que precisamente el abandono de tierras desde finales del siglo XIII fue algo habitual en toda Andalucía, situación que aprovecharon algunos para aumentar sus propiedades e incluso crearse pequeños señoríos ${ }^{81}$. Pero tampoco es desatinado pensar que esos terrenos fueran propiedad de Sancho Martínez, que los hubiera recibido en el repartimiento de Córdoba, al igual que fue dotado en el Repartimiento de Sevilla, que las hubiera entregado a su hija, y que posteriormente Garci Méndez hubiera establecido allí una población.

Corrobra la idea de que El Carpio había sido poblado recientemente la información de 1340, procedente de El libro del diezmo de los donadios de la catedral de Córdoba:

E agora, después que El Carpio se pobló en medio de los donadios, liéuanse todo lo menudo por fuerça, e echaron defensas e exidos e eras e poços en medio del dicho donadio que es ya tomado todo en Garçi Meléndez ${ }^{82}$.

Así pues, es perfectamente posible que Garci Méndez creara una nueva población en El Carpio mediante el traslado de los habitantes de Alcocer al amparo de una fortaleza que, según la lápida fundacional que conservamos, se realizó en 1325 . Conocieron esta inscripción, que actualmente se conserva en el Palacio de las Dueñas de Sevilla ${ }^{83}$, tanto Argote de Molina como Francisco Ruano, quienes la reproducen en sus libros. En ella se indicaba que Garci Méndez de Sotomayor, señor de Jódar, mandó construir el castillo de El Carpio. También se encargó de reformar el castillo de Jódar, cuyas obras se iniciaron en 1328, como indicó en una lápida que se colocó en esta fortaleza, actualmente desaparecida ${ }^{84}$.

Méndez de Sotomayor]: mas es cierto, que todo el terreno de este Lugar fue heredamiento de la Casa de Sotomayor". Ruano, La Casa de Cabrera, pp. 164-165.

80 Ruano, La Casa de Cabrera, 164.

81 González Jiménez, La repoblación de la zona de Sevilla.

82 Nieto Cumplido "El libro de los donadíos de la catedral de Córdoba", p. 52 y 162.

83 La lápida se encontraba en el castillo de El Carpio y fue trasladada al palacio de las Dueñas por el duque de Alba, Jacobo Suart y Falcó, en 1916. Su contenido es: "En el nombre de Dios. Amén. Esta obra mandó facer Garci Méndez de sotomayor, sennor de Xódar. E fízola maestre Mahomad. E fue obrero Ruy Gil. E fízose en la era MCCCLXIII annos. Christus vincit. Christus regnat. Christus imperat". Agradezco a Manuel Morales de Jódar que me facilitara la información del paradero de esta inscripción.

${ }^{84}$ Así, según indica Luis de Salazar, en el castillo de Jódar había una lápida con la siguiente inscripción: "En el nombre de Dios y Santa María. Este castillo y villa se comenzó a labrar en la era de MCCCLXVI. Hízolo García Meléndez, fijo de Alonso García de Sotomaior, el que hzo la torre y castillo del Carpio y la torre y castillo de Morente y la torre y Castillo de rezena y acabó el castillo de Jódar. Y fue el maestro que hizo esta torre maestre Hamete de Jahén, fijo del maestre Haco Aspo. Y fue obrero desta torre fra... Yañéz de Montoro. Este castillo 
Por lo tanto, la villa de Jódar debió de entrar a formar parte del señorío de los Méndez de Sotomayor a través del matrimonio de Garci Méndez con Juana Ruiz o Rodríguez, una de las herederas de Sancho Martínez de Jódar. Sabemos además que esta familia adquirió otras propiedades en la zona de Sierra Mágina, caso de los heredamientos de Nínchez y Chozas, cercanos a la villa de Garcíez, que es posible que llegaran a manos del linaje a través de la hija de Sancho Martínez de Jódar ${ }^{85}$. El interés de los Méndez de Sotomayor por mantener la villa poblada puede explicar que en 1331 Alfonso XI confirmara la exención que Sancho IV hizo a los pobladores del pago de moneda forera y servicio de ganado ${ }^{86}$.

Otra idea generalizada, siguiendo de nuevo a Gonzalo Argote de Molina, es que los Méndez de Sotomayor fueron señores de Jódar durante todo el siglo XIV y primeros años del siglo XV, hasta que Luis Méndez de Sotomayor vendió la villa al condestable Ruy López Dávalos ${ }^{87}$. Asimismo, en su estudio introductorio a la obra de Ruy González de Clavijo, Historia del Gran Tamorlán, realizado en 1582, indicaba que, a la vuelta de Samarcanda en 1406, uno de los embajadores, Payo Gómez de Sotomayor, después de desembarcar en Sanlúcar de Barrameda y en su camino hacia Alcalá de Henares, donde se encontraba Enrique III, hizo parada en Jódar, "que en aquella sazon era de Luis Mendez de Sotomayor su primo" "88. De nuevo la información es errónea, ya que, en primer lugar, y como veremos a continuación, entre los siglos XIV y XV el señorío de Jódar cambió en numerosas ocasiones de titularidad. Por otro lado, en 1406, Luis Méndez de Sotomayor había fallecido (ca. 1395), y el señor de El Carpio era su hijo Garci Méndez de Sotomayor ${ }^{89}$.

\section{Las vicisitudes del señorío de Jódar entre finales del siglo XIV y finales del siglo XV}

La convulsa vida política que sufrió Castilla en las últimas décadas del siglo XIV con un cambio dinástico y la subsiguiente alteración de la titularidad de numerosos señoríos castellanos afectó notablemente a Andalucía y particularmente al caso que estamos analizando. Desgraciadamente la falta de información nos impide conocer la situación política que vivieron los Méndez de Sotomayor en esos momentos, pero lo que sí tenemos claro es que en fechas cercanas a la guerra civil dejaron de controlar la villa de Jódar, que además experimentó entre el último cuarto del siglo XIV y durante todo el siglo XV continuos cambios de titularidad, sucediéndose varios señores de diferentes linajes.

En primer lugar, parece que fue señorío de doña Leonor Enríquez, hija del adelantado mayor de la frontera Enrique Enríquez ${ }^{90}$. Como caudillo mayor del obispado de Jaén tuvo bastante vinculación con este territorio, siendo durante un tiempo juez de

\footnotetext{
y esta villa y esta torre se labró en el tienpo que reinaua el mui noble rey D. Alfonso, fijo del mui noble rey don Ferrando, nieto del rey d. Sancho, reinantes en Castilla y León. Christus vincit. Christus regnat. Christus imperat". BRAH, Col. Salazar y Castro, M-95, f. 40r.

85 Carmona Ruiz, "La mentira como arma"

86 Porras Arboledas, "Fueros, privilegios y ordenanzas de la villa de Jódar", p. 400.

87 Argote De Molina. Nobleza de Andalucía, op. cit. p. 510.

88 Argote De Molina Introducción a Historia del Gran Tamorlán, p. 5.

89 Cabrera Sánchez. "El señorío de El Carpio", pp. 227-228.

90 Salazar y Castro, Historia Genealógica de la Casa de Lara, vol. 2, p. 426. Enrique Enríquez fue adelantado de la frontera durante el reinado de Pedro I.
} 
Baeza y señor de la aldea de Begíjar, perteneciente al concejo de Baeza ${ }^{91}$. Es posible que debido a esa relación con las tierras jiennenses consiguiera también convertirse en señor de Jódar, y que esta villa fuera parte del sustancioso patrimonio que doña Leonor debió heredar de su padre, entre el que se encontraban otras localidades del reino de Jaén, caso de La Higuera y el castillo de Recena ${ }^{92}$, muy cercano este último a la localidad de Jódar. Doña Leonor se casó en dos ocasiones, la primera con Alonso Pérez de Guzmán, III señor de Sanlúcar, que murió en 1365 en el asalto de Orihuela, y al que sucedió en sus estados su hermano Juan Alfonso de Guzmán ${ }^{93}$. Viuda sin hijos en 1367 contrajo matrimonio con el conde Fernando Ruiz de Castro, señor de Lemos, Monforte y Trastámara ${ }^{94}$.

Aunque desconocemos la fecha exacta del fallecimiento de don Enrique Enríquez, es de suponer que fue antes de 1368, fecha en que Pedro I otorgaba a Juan Alonso de Guzmán todos los bienes que don Enrique Enríquez tuvo en Andalucía ${ }^{95}$. Lógicamente esto tuvo que afectar a doña Leonor Enríquez, que se tuvo que ver privada de parte la herencia de su padre en beneficio de su cuñado, Juan Alfonso de Guzmán.

Posiblemente fue a partir de estas circunstancias cómo el señorío de Jódar y el resto de las propiedades jiennenses de doña Leonor Enríquez llegaron a manos de Juan Alfonso de Guzmán. De hecho, contamos con suficiente documentación para afirmar que, pese a lo alejado de su principal centro de acción, situado esencialmente en el reino de Sevilla, el conde de Niebla se preocupó de la villa de Jódar, como señor del lugar, buscando beneficios que sirvieran de atracción de nuevos pobladores. Así, sabemos que al menos en $1377^{96}$ y en $1380^{97}$ los reyes Enrique II y Juan I respectivamente, excusaron del pago de moneda forera a una serie de localidades y personas, estando entre ellas Jódar, donde se eximía del impuesto a 70 vecinos, especificándose además que esta localidad pertenecía a Juan Alfonso de Guzmán ${ }^{98}$.

Pero además hay más datos que corroboran este hecho y son los que aporta el Libro Registro Notarial de la villa de Torres. Así, en un asiento de 1394 aparece citado don Juan como conde de Jódar, e incluso se indica que una de las calles de la villa de Jódar se denominaba "calle del conde" 99 . Por otro lado, en otro asiento del mismo año se hace referencia a la intervención del conde en la avenencia entre unos vecinos "de Canena de Rus" ${ }^{100}$. Es un dato muy interesante ya que pese a la lejanía de Jódar del resto de sus propiedades don Juan Alfonso de Guzmán visitó en alguna ocasión este señorío,

91 García Fernández. Regesto documental, p. 77.

92 Fue señora de Melgar, Villalva, La Higuera, Jódar, Recena y Nogales. Salazar y Castro, Historia Genealógica de la Casa de Lara, vol. 2, p. 426.

93 Ladero Quesada. "Los Guzmán, señores de Sanlúcar, en el siglo XIV”, p. 232.

94 Salazar y Acha, La casa del rey de Castilla y León, p. 388.

95 1368, mayo, 1. Ladero Quesada. "Los Guzmán, señores de Sanlúcar, en el siglo XIV”, p. 232. Probablemente su fallecimiento fuera en 1366, aunque, según otras fuentes, no murió hasta 1376. Moxó, "La sociedad política castellana en la época de Alfonso XI".

96 Martín Rodríguez. "El Cuaderno de Monedas de 1377”, p. 357.

97 1380, noviembre, 10. Medina del Campo. Carta de Juan I relativa al cuaderno de las seis monedas. AM. Murcia, C.R. 1384-91, fol. 2, 9, 3. Edit. Díez Martínez, Colección de documentos, XI, doc. 54, pp. 97 y ss.

98 En el cuaderno de 1370 se indica "70 excusados en Jodar, lugar de Juan Alfonso de Guzmán”. Martín Rodríguez. "El Cuaderno de Monedas de 1377", p. 357. En el de 1380: "E en Xodar, lugar de don Johan Alfonso de Guzman, que non paguen estas dichas monedas fasta sesenta vezinos, e si mas oviere que paguen". Díez Martínez, Colección de documentos, XI, p. 104.

99 El Registro Notarial de Torres (1382-1400). Asiento 64.

$100 \quad$ Ibid. Asiento 67. 
e incluso, por su gran relevancia, debió intervenir en algunos asuntos locales, a veces de poca transcendencia, como es la de conseguir la concordia en el enfrentamiento entre dos vecinos de Canena.

Coincidiendo con el gobierno de Juan Alfonso de Guzmán y con una clara intención repobladora en 1379 el rey Juan I, además de confirmar la exención de moneda forera y de servicio de ganado concedida por Sancho IV, otorgó a Jódar dos importantes privilegios. Por una parte, eximió a los vecinos del pago de alcabalas tanto en la villa como en cualquier parte del reino, y les otorgó asimismo el privilegio de homicianos que tenía Alcalá la Real desde $1341^{101}$. En él se establecían prerrogativas tan importantes como la anulación de las deudas al que se avecindara en la villa y a sus hijos; la exención de responsabilidad al que hubiera matado, lisiado o hubiera cometido otro delito, excepto alevosía y traición, si se avecindara en la villa; libertad para una mujer casada que se refugiara en la villa con otro hombre que no fuera su marido ${ }^{102}$. Este tipo de privilegio era una de las reglamentaciones que más personalidad jurídica dio a los núcleos fronterizos durante la Baja Edad Media y se concedían con la principal intención de mantener habitados núcleos especialmente peligrosos por su proximidad al reino de Granada, mediante la acentuación de su defensa. Por ello, a partir del reinado de Alfonso XI se extendió por buena parte de los núcleos poblados de la frontera, que en el caso de la zona jiennense benefició anteriormente a Alcaudete, Castillo de Locubín, Alcalá la Real, Quesada, y posiblemente La Guardia y Pegalajar ${ }^{103}$. Que Jódar recibiera el privilegio de homicianos, así como la exención del pago de moneda forera y alcabalas nos muestra las dificultades que había de repoblar esta villa y que se buscaran diferentes mecanismos para hacer el territorio atractivo a nuevos pobladores.

En el testamento de Juan Alfonso de Guzmán no consta la villa de Jódar, como tampoco las otras posibles propiedades que debió de recibir en el reino de Jaén, lo que nos hace suponer que, en una fecha indeterminada entre 1380 y 1394, debió de deshacerse de ellas. Desgraciadamente tenemos un importante vacío de información, lo que nos lleva a barajar meras hipótesis. Como ya hemos visto, Gonzalo Argote de Molina decía erróneamente que Luis Méndez de Sotomayor había vendido la villa al condestable Ruy López Dávalos ${ }^{104}$.

Sin embargo, y a la vista de la información que tenemos, podemos suponer que es más probable que el que vendiera Jódar al condestable fuera Juan Alfonso de Guzmán. Tampoco está clara la fecha de la posible transacción. Así, algunos autores, sin indicar de dónde han obtenido la información, nos dan incluso algunas fechas para la compra de Jódar por el condestable. Luis Blanco y Blanco dice que la venta al condestable se realizó en $1371^{105}$, algo improbable, ya que Ruy López Dávalos era muy joven (sólo tenía 14 años) y todavía no se había iniciado su ascenso social. Por su parte Tomás Márquez de Castro fechó la compra en $1393^{106}$, lo que también es imposible ya que, en aquel tiempo, como hemos visto, la villa de Jódar aún pertenecía a Juan Alfonso de Guzmán, conde de Niebla.

\footnotetext{
101 1379, agosto, 15. Cortes de Burgos. Edit. Porras Arboledas. "La organización militar y social de la frontera jiennense", pp. 493-495.

102 Id. y Porras Arboledas, Fueros, privilegios y ordenanzas de la villa de Jódar, pp. 400-401.

103 Porras Arboledas, Fueros, privilegios y ordenanzas de la villa de Jódar, p. 401.

104 Argote De Molina, Nobleza de Andalucía, p. 510.

105 Blanco y Blanco. "Jódar y su castillo o Fortaleza", p. 362.

106 Márquez de Castro. Títulos de Castilla, p. 129.
} 
Además de Jódar, Ruy López Dávalos dispuso de numerosos bienes en el reino de Jaén, y fue la mano derecha de Juan II hasta 1422, fecha en que cayó en desgracia, por lo que el monarca le confiscó sus bienes ${ }^{107}$. Fernando de Torres, alguacil mayor de Jaén, fue el encargado de la ocupación del castillo de Jódar tras la huida del condestable, donde, según Argote de Molina guardaba su cuantioso capital ${ }^{108}$.

El reparto de las propiedades de Ruy López Dávalos en 1423 supuso que las tierras localizadas en el reino de Jaén, pasaran a manos de Fadrique de Castro, conde de Trastámara, quien recibió además del ducado de Arjona, La Higuera, cerca de Arjona, Recena, parte de Jimena, parte de Ibros y Jódar ${ }^{109}$. Como señor de Arjona y Jódar, en 1426, Juan II le ordenaba que aprestara a gentes de estas dos localidades para luchar contra los granadinos ${ }^{110}$. Pero Jódar quedó poco tiempo en manos del duque, ya que en 1428, poco antes del comienzo de su decadencia, donaba este señorío a Juan de Perea ${ }^{111}$ y a su mujer, Beatriz García de Villandrando ${ }^{112}$. Según señaló el propio Fadrique de Castro en el documento de donación, les entregó esta villa como compensación a las propiedades que su tío, el almirante don Alfonso Enríquez, les había tomado en las Torre de Reinoso, Barrio Melgar y Santa Cruz ${ }^{113}$.

El reparto de la herencia de Juan de Perea, tras el fallecimiento en 1435, fue bastante complicado, y a consecuencia de ello en 1436 su hermano Rodrigo de Perea, adelantado de Cazorla, se apoderó de la fortaleza y villa de Jódar, por lo que sus tres sobrinos iniciaron un pleito contra él ${ }^{114}$. No conocemos la resolución del mismo, ya que la muerte del adelantado en 1438 en el combate de los Tubos junto a Castril (Granada) debió de influir notablemente ${ }^{115}$.

En cualquier caso, a partir de estas fechas la propiedad de la villa de Jódar vuelve a entrar en una nebulosa documental hasta 1453, fecha en que sabemos que Pedro de Zúñiga controlaba la villa de Jódar. Ese año el conde de Plasencia realizó un codicilo en el que dejaba a su nieto Fernando de Zúñiga, hijo del conde de Trastámara ${ }^{116}$, la villa y castillo de Jódar. En él establecía además que, en caso de fallecimiento de Fernando sin descendencia, los derechos de herencia de la localidad recayeran en su hermana Leonor de Pimentel ${ }^{117}$ y si ésta tampoco viviera, en Diego y Álvaro de

107 Guerrero Navarrete. Proceso y sentencia contra Ruy López Dávalos, Suárez Fernández, “Auge y caída de un hombre nuevo", Ruano Prieto, "El condestable d. Ruy López Dávalos".

108 Argote de Molina, Nobleza de Andalucía, pp. 649-650.

109 Franco Silva, "El señorío de Villafranca del Bierzo", p. 25. Pardo de Guevara, Los señores de Galicia, vol. 1, p. 277.

110 1426, abril, 16. Toro. Archivo Ducal de Alba, Sección Lemos, C-2-76. Reg. Pardo de Guevara, Los señores de Galicia, vol. 2, p. 69.

111 Éste era señor de Vellosillo de Esgueva, de Santa Cruz y de las Torres de Reinoso, vecino y regidor de Valladolid, corregidor de Zamora y vasallo de Juan II. Vid. Ceballos-Escalera Gila. “Un antiguo mayorazgo palentino”, p. 122.

112 Pertenecía a uno de los linajes más importantes de Palencia, los Villandrando. Era hija de Ruy García de Villandrando, señor de Fuensaldaña, y de María Rodríguez Osario. Fue señora de las Torres de Reinoso y Santa Cruz, siendo adquirido este último junto a su marido Juan de Perea. Vid. Ceballos-Escalera Gila, "Un antiguo mayorazgo palentino", pp. 121-122.

113 1428, febrero, 16, Yanguas. Escritura de donación de la villa de Jódar, otorgada por Fadrique de Castilla, duque de Arjona, a favor de Juan de Perea. BRAH, Col. Salazar y Castro, M-91, ff. 123 a 128.

114 Ceballos-Escalera Gila, "Un antiguo mayorazgo palentino", p. 123. Los hijos de Juan de Perea eran Juan, Íñigo y Catalina.

115 Argote de Molina, Nobleza de Andalucía, p. 710.

116 Fernando Osorio era hijo de Pedro Álvarez Osorio, conde de Trastámara, y de doña Elvira de Zúñiga, hija de don Pedro de Zúñiga y hermana de Diego y Álvaro de Zúñiga. Vid. Salazar y Acha "Los Osorio Un linaje de más de mil años", p. 168.

117 Leonor de Pimentel era hija de Elvira de Zúñiga y de Juan Alonso de Pimentel, conde de Mayorga, su primer marido. 
Zúñiga recibiendo cada uno la mitad de la villa ${ }^{118}$. Esto último contradice la idea de Salazar, siguiendo a Pellicer, de que Pedro de Zúñiga estableció un mayorazgo con ella $^{119}$.

No conocemos las circunstancias en las que Pedro de Zúñiga adquirió la villa de Jódar, aunque es de suponer que fue la propia Beatriz García de Villandrando la que se la vendió. En el testamento de doña Beatriz, realizado en $1464^{120}$, su hija Catalina le reclamaba los derechos a la tercera parte de Jódar, o en su defecto 3.000 doblas de oro, como heredera de su padre, Juan de Perea, y en virtud de un contrato que decía que su madre había establecido con ella. Ante ello doña Beatriz alegaba que ella no había realizado tal contrato. Además, manifestaba que en la donación de don Fadrique no constaba ninguna obligación y que éste había hecho la donación como compensación a la usurpación de Barrio Melgar, que era herencia suya ${ }^{121}$. Con ello claramente estaba indicando que había dispuesto libremente de la villa de Jódar por lo que su hija no podía requerirle nada. Dado que doña Catalina le reclamaba 3.000 doblas de oro es de suponer que la villa de Jódar se había vendido previamente por 9.000 doblas de oro, puesto que lo que pedía era una tercera parte de su valor. Tampoco conocemos la fecha en que se pudo realizar la transacción, pero dado que en el testamento que realizó Pedro de Zúñiga en marzo de $1450^{122}$ no hay ninguna alusión a Jódar, y que en el codicilo de 1453 sin embargo se hace mención expresa a esta villa como una forma de acrecentamiento de la herencia de su nieto Fernando, es de suponerse que el conde de Plasencia la tuvo que adquirir entre marzo de 1450 y junio 1453.

Tampoco estuvo mucho tiempo la villa en manos de los Zúñiga, ya que en 1460 el conde de Miranda, Diego de Zúñiga, garantizaba que, dado que se había capitulado el matrimonio de su hija Constanza con Alfonso Téllez Girón, hijo del maestre don Pedro Girón, el conde de Plasencia, Álvaro de Zúñiga, su hermano, o su sobrino, don Fernando, venderían antes de un año la villa y fortaleza de Jódar al maestre de Calatrava para su hijo Alfonso ${ }^{123}$. Esta compra estaba ya pactada previamente ${ }^{124}$, y Diego de Zúñiga pudo persuadir a su sobrino, que entonces era menor de edad, y a su hermano para que accedieran a la venta de la localidad. De hecho, y pese a que el matrimonio no llegó a efectuarse, en septiembre de 1461 Juan de Navarrete, como alcaide de Jódar, realizaba pleito homenaje a Pedro Girón ${ }^{125}$. No obstante, y pese a que Fernando de Zúñiga accedió a esta transacción, en 1483 reclamó su titularidad alegando que era menor de edad y que Pedro Girón lo había engañado, iniciando un pleito con el entonces propietario de la villa, Día Sánchez de Carvajal que se resolvería tras el fallecimiento de don Fernando, como veremos más adelante.

118 1453, junio, 25. Béjar. Sección Nobleza del Archivo Histórico Nacional (en adelante SNAHN), Osuna, C. 215, D. 45 .

119 Salazar y Castro, Advertencias Históricas, p. 150.

120 Un estudio de este testamento en: Izquierdo García et alii, "Testamentos femeninos vallisoletanos".

121 AHN, Clero, leg. 7716. En Izquierdo García et alii, "Testamentos femeninos vallisoletanos" se interpretan erróneamente sus palabras diciendo que en el testamento "prevé Beatriz que Catalina pudiese reclamar la tercia que le pertenece como heredera de Perea (o su valor en oro)" p. 290, cuando lo que realmente doña Beatriz indica que ella podía disponer de Jódar libremente ya que era una compensación por unas propiedades suyas que le había usurpado.

122 1450, marzo 11. Béjar. SNAHN, Osuna, C.215 D. 42. Testamento de Pedro de Zúñiga.

123 1460, noviembre, 14. Medina del Campo. SNAHN. Frías, C.658, D.9

124 Viña Brito, "Don Pedro Girón", p. 278.

125 1461, septiembre 24. Almagro. SNAHN. Frías, C. 696, D. 25. 
Tras la adquisición de la villa de Jódar, Pedro Girón siguió administrándola en nombre de su hijo Alfonso Téllez Girón debido a su corta edad, confiando en 1463 a Día Sánchez de Carvajal su guardia y custodia, haciéndole éste juramento y pleito homenaje de que la defendería siempre por el maestre y su hijo Alfonso y que los acogería, así como a sus criados, que cumpliría siempre sus órdenes y que no se la entregaría nunca a ninguna persona poderosa sin expreso mandato de Pedro Girón ${ }^{126}$.

Día Sánchez de Carvajal era un regidor baezano que pertenecía a una familia de hidalgos que se había asentado en Baeza ${ }^{127}$ y que había entrado al servicio del maestre desde joven como criado. Gracias a su relación con don Pedro Girón se vio notablemente favorecido, convirtiéndose en su hombre de confianza en el reino de Jaén ${ }^{128}$, por lo que le recompensó con importantes beneficios. Así, en 1462 le entregó, como regalo de bodas, los portazgos de Baeza y Úbeda, En 1465 le cedió el puerto seco de Quesada, el portazgo y almojarifazgo de Jaén y el diezmo y medio diezmo de lo morisco y la escribanía de las rentas del obispado y, posiblemente en la misma fecha, la villa de Jódar, de la que, como hemos visto, era alcaide desde $1463^{129}$. Por otro lado, aprovechando el incremento de su hacienda, Día Sánchez de Carvajal realizó algunas operaciones personales para mejorar su patrimonio, destacando entre ellas la compra en 1463 del señorío de Tobaruela ${ }^{130}$.

No sabemos exactamente cuándo se produjo la donación de la villa de Jódar a Día Sánchez de Carvajal, tan sólo que el responsable del traspaso fue el bachiller Ferrand Gómez de Herrera, criado del maestre, quien anteriormente se había encargado también de su compra a los Zúñiga, aunque suponemos que ésta se debió de producir en torno a 1465, a la par que el resto de cesiones. Al parecer, la entrega de Jódar al Carvajal se estableció con una serie de condiciones, según se indica un documento de renuncia del primogénito del maestre, Alfonso Téllez Girón, realizado en 1467. Según indica en el citado escrito, era mayor de 14 años y no tenía ya tutor (que hasta el momento había sido Enrique de Figueredo), por lo que ratificaba las mercedes que su padre había hecho a Día Sánchez de Carvajal.

Según consta en el documento, Pedro Girón cedió la villa y fortaleza de Jódar a Día Sánchez de Carvajal con una serie de reservas. Así, se estipuló que en caso de que Día Sánchez de Carvajal muriera sin hijo varón legítimo, la villa debía pasar a manos de Juan Pacheco, su hijo ${ }^{131}$, con el compromiso de que éste se casara con la hija legítima del Carvajal. En caso de que este hijo del maestre muriera o entrara en orden religiosa antes de que lo heredara, quedaría en manos de otro de los hijos del maestre con la misma obligación de matrimonio. Finalmente, en caso de que

126 1463, marzo 17. Arjona. SNAHN. Frías, C. 658, D. 12. Franco Silva, “Don Pedro Girón”, pp. 83-84.

127 El linaje de Carvajal procedía del reino de León. Al servicio de Castilla, participó en las conquistas de Fernando III, estableciéndose en tierras extremeñas. De ellos, hay que destacar a Juan Alfonso de Carvajal, ballestero mayor del rey, que fue ajusticiado por orden de Fernando IV en la peña de Martos, de quien al parecer desciende su rama andaluza, que asentada en la ciudad de Baeza participó activamente en el gobierno de la ciudad, así como en las luchas fronterizas contra el reino de Granada.

128 En este sentido debemos destacar cómo en el enfrentamiento de Enrique IV con la nobleza a partir de 1464, Día Sánchez de Carvajal consiguió sumar para la causa nobiliaria las ciudades de Úbeda y Baeza y los castillos de su entorno. Vid. Quesada Quesada, "La supresión de la aduana", p. 35.

129 Vid. T. Quesada Quesada. "Una tierra fronteriza con el Reino de Granada”, pp. 177-198, "El arancel de portazgo de Baeza de fines del siglo XV", pp. 23-49, "La supresión de la aduana", pp. 33-46. La Serranía de Mágina, p. 140.

130 Un estudio de este señorío en Carmona Ruiz, "El señorío de Tobaruela"

131 En el documento se dice "Don Juan Pacheco mi hermano [en relación a Alonso Téllez Girón], fijo del dicho señor maestre". 
no quedara ningún hijo varón que se casara con la hija de Día Sánchez de Carvajal, entonces la localidad de Jódar debía pasar a manos de Alfonso Téllez Girón, que debía de dar a su hija en compensación 500.000 mrs. En noviembre de 1467, Alfonso Téllez Girón, I conde de Ureña, renunciaba a todos los derechos que pudiera tener sobre la villa, así como a los portazgos de Úbeda y Baeza, a cambio de 10.000 doblas castellanas de oro $^{132}$. Este documento resulta un tanto extraño ya que un mes antes Alfonso Téllez Girón había firmado otro por el que confirmaba todas las mercedes "así de vasallos, como de juro de heredad, y portadgos, escrivanías, pechos y derechos y otras rentas de maravedís y joyas y plata y otras cosas" a Día Sánchez de Carvajal, comprometiéndose al pago de 3000 doblas en caso de que lo incumpliera a favor de Día Sánchez ${ }^{133}$. Quizás se elaborara un acuerdo específico relacionado con Jódar al estar sujeta la donación de esta villa a una serie de condiciones particulares y la renuncia a sus derechos supuso para los Téllez-Girón un importante beneficio económico.

En cualquier caso, los problemas en la transmisión del señorío de Jódar al linaje de los Carvajal no acabaron con la confirmación de los Téllez Girón de la donación, ya que, como hemos indicado anteriormente, en 1483 Fernando de Zúñiga, arcediano de Sevilla y señor de Villarín, iniciaba un pleito reclamando sus derechos a la villa de Jódar. Así, alegaba que tras haber heredado la fortaleza de su abuelo Pedro de Zúñiga, Pedro Girón se la había quitado y que, al reclamársela, el maestre de Calatrava le había insinuado que se la tenía que vender. Ante ello, y viendo el poder del maestre le aconsejaron que renunciara a su pretensión, por lo que hizo el contrato de venta, siendo aún menor de edad. Además, se quejaba que su procurador, el bachiller Herrera, la había vendido por la mitad de su justo precio y que, aunque en el contrato de compra-venta se expresaba que se daba por satisfecho, en realidad no era así, alegando para ello que era en ese momento menor de edad, por lo que reclamaba la titularidad de la villa ya que Día Sánchez de Carvajal la tenía ilegítimamente. Por ello pedía a Lope García de Salazar, provisor del arzobispado de Sevilla, que le relajase del juramento que había hecho en el contrato de no actuar contra la venta, a fin de iniciar pleito contra Día Sánchez de Carvajal. El provisor consideró que era justa su demanda por lo que aceptó esa petición ${ }^{134}$. Ante ello, Día Sánchez de Carvajal demandó a Fernando de Zúñiga ante la Iglesia de Sevilla alegando el incumplimiento de juramento. Por ello, Francisco Pérez, racionero de Sevilla y juez eclesiástico, pidió en 1485 a los Reyes Católicos que sobreseyeran el pleito que estaba en el Consejo Real, al estar bajo jurisdicción eclesiástica ${ }^{135}$.

El proceso debió seguir su curso con Fadrique Osorio, sobrino de Fernando de Zúñiga y heredero de éste. Finalmente en 1511 Mencía de Guzmán, su viuda, en nombre y como tutora de sus hijos Gonzalo Osorio e Isabel de Guzmán, estableció un acuerdo con Alonso de Carvajal, sucesor de Día Sánchez, por el que finalizó el pleito a cambio de dos millones de maravedís, repartidos entre sus hijos de la siguien-

132 1467, noviembre, 29. Almagro. BRAH, Col. Salazar y Castro, M-91, ff. 271-274v.

133 1467, octubre, 28. Almagro. BRAH, Col. Salazar y Castro, M-91, ff. 299-300. Posiblemente este documento está relacionado con el que Juan Pacheco, marqués de Villena, y tío del conde de Ureña, realizó el 29 de noviembre de 1467 , por el que ratificaba los acuerdos que su sobrino había realizado con Día Sánchez de Carvajal. 1467, noviembre, 29. Medina del Campo. BRAH, Col. Salazar y Castro, K-37, f. 39. Edit. Toral Peñaranda, Úbeda (1442-1510), pp. 112-113.

134 1483, diciembre, 10. Sevilla. BRAH, Col. Salazar y Castro, M-128, ff. 38v-40v.

135 1485, agosto, 11. Sevilla. BRAH, Col. Salazar y Castro, M-128, ff. 40v-42r. 
te manera: 1.375.000 maravedís para la dote de Isabel de Guzmán en el matrimonio concertado con Diego de Carvajal, heredero del señorío, 375.000 maravedís para su hijo Gonzalo Osorio, mientras que los 250.000 maravedís restantes se repartirían entre ambos hermanos, comprometiéndose además a dar a Gonzalo Osorio 50.000 maravedís de renta anual vitalicia ${ }^{136}$.

\section{Conclusiones}

A lo largo de estas páginas hemos visto que el señorío de Jódar cambió de manos en numerosas ocasiones entre los siglos XIV y XV. Esos cambios se debieron a varias razones y desgraciadamente ninguna positiva. En parte como consecuencia de la convulsa vida política que Castilla vivió en esas fechas, en que, en primer lugar, hubo un cambio dinástico, que supuso que muchos nobles que fueron leales a Pedro I se vieran despojados de sus señoríos, mientras que los que apoyaron a Enrique II recibieron nuevos dominios. Pero además, se produjeron varios gobiernos en minoría de edad y numerosos enfrentamientos nobiliarios que provocaron ensalzamientos y defenestraciones de muchos miembros de la nobleza, lo que supuso igualmente cambios en la titularidad de los señoríos. En medio de esta situación los reyes utilizaban la donación y confiscación de señoríos como una forma de castigo y premio, de atracción de la nobleza y compra de fidelidades. Los problemas de Leonor Enríquez para heredar a su padre, el ascenso de Alonso de Guzmán o del condestable Dávalos son ejemplo de esta realidad.

A ello hay que unir el hecho de que la nobleza en esa época entendía sus estados señoriales como mera fuente de ingresos. Así, normalmente residían en las ciudades, mientras que los castillos quedaban bajo el control de sus alcaides. Por ello, cuando consideraban que los beneficios que podían obtener no eran suficientes los vendían o los utilizaban como forma de pago de sus deudas, sin olvidar nunca los cambios de titularidad a consecuencia de los repartos de herencias. En esta época Jódar no debía ser una villa especialmente rentable considerando su situación en primera línea de frontera. De hecho, en esas circunstancias el desarrollo económico estaba bastante limitado, con una agricultura bastante escasa, que obligaba al abastecimiento desde localidades del interior, lo que encarecía su precio, mientras que las principales actividades eran la ganadería, el comercio, el pillaje al otro lado de la frontera y el contrabando ${ }^{137}$.

La situación cambió radicalmente a finales del siglo XV con el fin de la Guerra de Granada, que supuso la expansión económica de Andalucía, y especialmente de las localidades situadas en la frontera, produciéndose una diversificación económica, con un considerable aumento de los espacios cultivados, y un importante crecimiento demográfico. A partir de entonces la agricultura tendría cada vez más importancia en detrimento de la ganadería que vio como progresivamente se reducían los espacios pastoriles. Coincidió toda esta transformación con la llegada al señorío de los Carvajal, que vieron cómo paulatinamente aumentaban sus ingresos. Si a finales del siglo XIV suponemos que en Jódar habría unos 70 vecinos, según se puede deducir

\footnotetext{
136 1511, abril, 17. Córdoba. BRAH, Col. Salazar y Castro, M-128, ff. 27-38.

137 Sobre los aprovechamientos de la frontera entre los reinos de Jaén y Granada vid. Argente del Castillo Ocaña. "Los aprovechamientos pastoriles" y "Las actividades agroganaderas en la Frontera, y Carmona Ruiz. "
} 
del número de excusados en 1377 y 1380, el crecimiento se puede comprobar si lo comparamos con los datos que tenemos para 1520 en que había unos 200 vecinos, mientras que en 1578, Jódar contaba con 550 vecinos ${ }^{138}$.

Tras la conquista de Granada y la desaparición de la frontera se inició un nuevo ciclo para Jódar en el que el notable crecimiento económico beneficiaría no sólo a su población sino también a sus señores, los Carvajal, que convirtieron a la villa en su principal foco de interés. Muestra de ello son los sustanciosos pagos que realizaron tanto a los descendientes de Pedro Girón como a los de Fernando de Zúñiga para consolidar sus derechos sobre esta localidad. Además, y para evitar futuras fragmentaciones, Día Sánchez de Carvajal creó un mayorazgo en el que además de Jódar se incluía la villa de Tobaruela y otros bienes y derechos ${ }^{139}$.

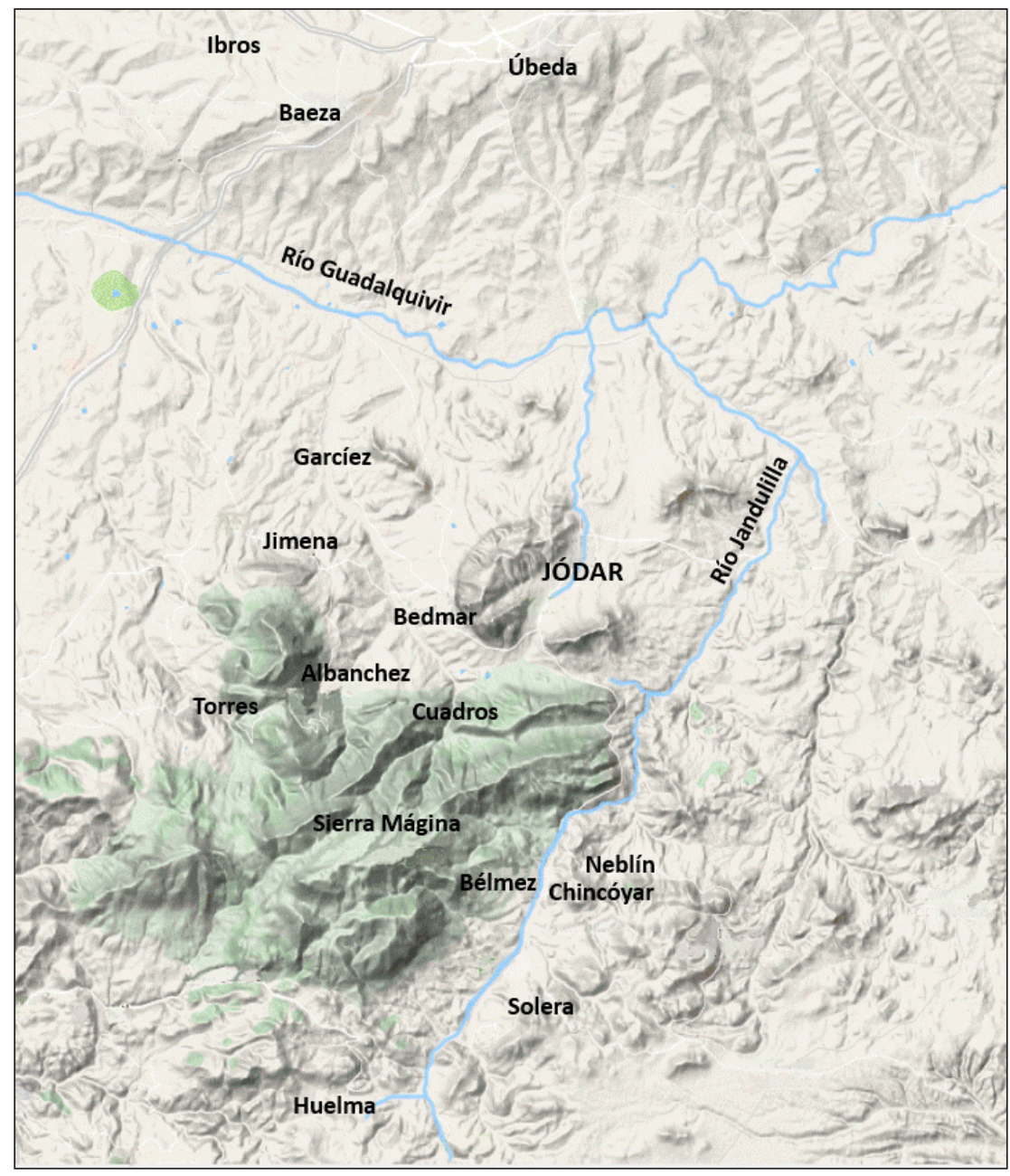

138 En 1578 se indica que "La villa tiene 600 casas y 550 vecinos poco más o menos. Que en tiempos de las comunidades había sólo 200 vecinos y que después a crecido". Villegas Díaz "Relación de los pueblos de Jaén”, p. 169.

139 1477, febrero, 23. Toledo. Los Reyes Católicos autorizan a Día Sánchez de Carvajal para hacer un mayorazgo a favor de su hijo Alfonso de Carvajal. Archivo General de Simancas, RGS, 147702,49. Vid. También. Quesada Quesada "La fortuna de un miembro de la pequeña nobleza", pp. 79-101. 


\section{Bibliografía}

Afonso, Pedro, conde de Barcelos, Livro de linhagens do conde don Pedro, ed. crítica por José Mattoso, Lisboa: Academia das Ciências, 1980, 2 vols.

Alcalá Moreno, Ildefonso, Historia del castillo de Jódar. Nuevas fuentes documentales para el revisionismo de la historia de Jódar. Granada: Ediciones Mágina, 2011.

— "Los castillos y fortalezas del curso bajo del Río Jandulilla. El castillo de Xandulilla y la Villa de Félix. Una aproximación al control de la tierra por parte del señorío de Jódar y el sistema defensivo de la zona a través de las fuentes documentales", Sumuntán: anuario de estudios sobre Sierra Mágina, 29 (2011) 197-248.

Argente del Castillo Ocaña, Carmen. "Los aprovechamientos pastoriles en la Frontera Granadina". Andalucía entre Oriente y Occidente (1236-1492). Actas del V Coloquio Internacional de Historia Medieval de Andalucía. Córdoba, 1988, pp. 271-280.

— "Las actividades agroganaderas en la Frontera". II Estudios de Frontera. Actividad y vida de frontera. Jaén, 1998, pp. 73-99.

Argote de Molina, Gonzalo. Nobleza de Andalucía. Jaén: Riquelme y Vargas, 1991.

- Introducción a Historia del Gran Tamorlán... y un breve discurso fecho por Gonzalo Argote de Molina. Madrid, $1782^{2}$.

Ballesteros Beretta, Antonio. Alfonso X El Sabio. Barcelona: El Albir, 1984.

Blanco y Blanco, Luís, "Jódar y su castillo o Fortaleza”. Don Lope de Sosa, 1913, p. 362.

Cabrera Muñoz, Emilio, "La señorialización de Andalucía en el siglo XIII y los orígenes de la primera casa de Aguilar", Historia. Instituciones. Documentos, 31, 2004, pp. 69-96.

- "Nobleza y señoríos en Andalucía durante la Baja Edad Media" La nobleza peninsular en la Edad Media, León, 1999, pp. 89-119

— "Feudalismo y señoríos en Andalucía (siglos XIII al XV)" Historia de Andalucía. IV. El nacimiento de Andalucía, M. González dir. Barcelona: Planeta, 2006, vol. IV, pp. 106-133.

— "Repoblación y señoríos en Andalucía (siglos XIII y XIV) en B. Arizaga et alii (ed.) Mundos Medievales. Espacios, sociedades y poder. Homenaje al profesor José Ángel García de Cortázar y Ruiz de Aguirre, Santander: Universidad de Cantabria, 2012, pp. 1109-1124.

— "El señorío de El Carpio en el siglo XV". Aragón en la Edad Media 14-15 (1999), pp. 227-242.

Carmona Ruiz, Ma Antonia. "El señorío de Tobaruela (Jaén) a fines de la Edad Media”. Historia, Instituciones, Documentos, 30 (2004), pp. 113-130.

- "La mentira como arma. Pleitos en torno a la propiedad de un mayorazgo. Nínchez y Chozas (ss. XV-XVI)". Historia. Instituciones. Documentos. 36 (2009), pp. 111-136.

— "En torno al origen de los señoríos del reino de Jaén. La génesis del linaje de los Quesada, señores de Garcíez y Santo Tomé (Jaén). Siglos XIII-XIV". Medievalismo, 27 (2017).

Ceballos-Escalera Gila, Alfonso de. "Un antiguo mayorazgo palentino: El de los Señores de Santa Cruz, Castillejo y las Torres de Reinoso" Publicaciones de la Institución Tello Téllez de Meneses, $\mathrm{N}^{\circ} .78$ (2007), pp. 115-140. 
Collantes de Terán Sánchez, Antonio, “Los señoríos andaluces. Análisis de su evolución territorial en la Edad Media", Historia. Instituciones. Documentos, 6 (1979) 89-112.

Colección de Documentos Inéditos para la Historia de España, t. CXII, Madrid, 1895.

Crónica de Fernando IV, ed. Cayetano Rosell, Madrid: Biblioteca de Autores Españoles, LXVI, 1953.

Díez Martínez, José Manuel, Bejarano Rubio, Amparo, Molina Molina, Ángel Luis, Colección de documentos para la historia de Murcia, XI. Documentos de Juan I. Murcia, 2001.

Franco Silva, Alfonso. "Don Pedro Girón, fundador de la Casa de Osuna (14231466)". Osuna entre los tiempos medievales y modernos, Sevilla: Universidad, 1995, pp. 63-94.

— "El señorío de Villafranca del Bierzo (siglos XIV y XV)". La fortuna y el poder. Estudios sobre las bases económicas de la aristocracia castellana (S. XIV-XV). Cádiz, 1996, pp. 17-135.

García Fernández, Manuel "Regesto documental andaluz de Alfonso XI", Historia. Instituciones. Documentos, 15, (1988), pp. 1-125.

González González, Julio. Reinado y diplomas de Fernando III, Córdoba: Caja de Ahorros, 1980-1986, 3 vols.

González Jiménez, Manuel (ed.), Diplomatario Andaluz de Alfonso X, Sevilla: El Monte, 1991.

- (2001). La repoblación de la zona de Sevilla durante el siglo XIV, Sevilla: Universidad, $2001^{3}$.

- Alfonso X el Sabio, Barcelona: Ariel, 2004.

— "Baeza después de la conquista. Repoblación y organización de un espacio", en Carmona Ruiz, Ma Antonia (coord.). Fuero de Baeza. Estudios Introductorios, edición de Jean Roudil y Facsímil, Jaén: 2010, pp. 31-48.

González Jiménez, Manuel y Molina Molina, Ángel Luis. Los milagros romanzados de Santo Domingo de Silos de Pero Marín, Murcio: real Academia de Alfonso X el Sabio, 2008.

Guerrero Navarrete, Yolanda. Proceso y sentencia contra Ruy López Dávalos, condestable de Castilla, Jaén: Instituto de Estudios Giennenses, 1982.

Ibn Abī Zar'. Raw ḍ al-Qirțās, trad. A. Huici Miranda. Valencia, 1964, vol. 2.

Izquierdo García, Ma Jesús y Olivera Arranz, Ma Rosario, “Testamentos femeninos vallisoletanos del siglo XV. La voz airada de Beatriz García de Villandrando". Historia. Instituciones. Documentos, 18 (1991), 263-295.

Jiménez de Rada, Rodrigo. Historia de los hechos de España. Ed. J. Valverde, Madrid: Alianza, 1989.

Ladero Quesada, Miguel Ángel, "Sociedad feudal y señoríos en Andalucía” En torno al feudalismo hispánico, León, 1989, pp. 453-460.

— "Los Guzmán, señores de Sanlúcar, en el siglo XIV”, Historia. Instituciones. Documentos, 36 (2009), pp. 229-250.

Márquez de Castro, Tomás, Títulos de Castilla y señoríos de Córdoba y su reino. (1779). Edición y estudio preliminar de José Manuel de Bernardo Ares. (Córdoba, 1981).

Martín Rodríguez, José Luis, “El Cuaderno de Monedas de 1377”, Historia. Instituciones. Documentos, 4 (1977), pp. 355-380.

Memorial Histórico Español, vol. 1, Madrid, RAH, 1851. 
Moxó, Salvador de "De la nobleza vieja a la nobleza nueva. Transformación nobiliaria castellana en la Baja Edad Media" Cuadernos de Historia (Anexos de la revista Hispania), 3 (1969), pp. 1-210.

— "La sociedad política castellana en la época de Alfonso XI", Cuadernos de Historia. Anexos de Hispania, 6 (1975), pp. 187-326.

Nieto Cumplido, Manuel "El libro de los donadíos de la catedral de Córdoba". Cuadernos de estudios medievales y ciencias y técnicas historiográficas, No. 4-5 (1979), pp. 125-162.

Olmo López, Antonio, Las subbéticas islámicas de Jaén y Granada. Evolución territorial. De los antecedentes romanos a la conquista cristiana, Jaén: Instituto de Estudios Giennenses, 2001.

Pardo de Guevara y Valdés, Eduardo. Los señores de Galicia, tenentes y conde de Lemos en la Edad Media, 2 vols. La Coruña, 2000.

Porras Arboledas, Pedro. "La organización militar y social de la frontera jiennense en la Edad Media". La sociedad medieval andaluza, grupos no privilegiados: Actas del III Coloquio de Historia Medieval Andaluza, Jaén, 1984, pp. 475-500.

— "Fueros, privilegios y ordenanzas de la villa de Jódar. Cinco siglos de derecho municipal". Historia. Instituciones. Documentos, 21 (1994), pp. 391-422.

Primera Crónica General. Estoria de España que mandó componer Alfonso el Sabio y se continuaba bajo Sancho IV en 1289. Ed. Ramón Menéndez Pidal. Madrid, $1955\left(1906^{1}\right)$.

Quesada Quesada, Tomás “Una tierra fronteriza con el Reino de Granada: el valle del Jandulilla”. Cuadernos de Estudios Medievales, XII-XIII (1984), pp. 177-198.

— "El arancel de portazgo de Baeza de fines del siglo XV". Boletín de Estudios Giennenses, XXXIII, 130 (1987), pp. 23-49.

Quesada Quesada, Tomás, "La supresión de la aduana y portazgo de Jaén en 1491". Cuadernos de Estudios Medievales, XIV-XV (1988), pp. 33-46.

— "La fortuna de un miembro de la pequeña nobleza al final de la Edad Media: Los bienes de Alonso de Carvajal, señor de Jódar". Hispania, XLVIII/168 (1988), pp. 79-101.

- La Serranía de Mágina en la Baja Edad Media. Una tierra fronteriza con el Reino Nazarí de Granada. Granada: Universidad, 1989.

— "Los pactos de sumisión de los mudéjares de la Serranía de Mágina (Jaén) y su significado económico", IV Simposio Internacional de Mudejarismo: Economía, Teruel, 1993, pp. 521-528.

- "Formas de poblamiento en un área rural de al-Andalus: el valle del río Jandulilla", Arqueología y Territorio Medieval, 2 (1995) 5-24.

Quintanilla Raso, Ma Concepción, "La sociedad política. La nobleza" I Encuentro de Historia Medieval de Andalucía, M. García Fernández ed. Sevilla, 1999, pp. 107-124.

— "La nobleza en Andalucía del siglo XV. Identidad y representación del poder nobiliario señorial". Historia de Andalucía. VIII Coloquio, Granada, 2009, pp. 228-259.

Rades y Andrada, Francisco, Crónica de las tres Órdenes de Santiago, Calatrava y Alcántara. Toledo, 1572 (ed. facs. 1980).

El Registro Notarial de Torres (1382-1400): edición y estudios. [Sevilla]: Junta de Andalucía. Consejería de Cultura y Deporte, 2012. 
Rodríguez Molina, José. El reino de Jaén en la Baja Edad Media. Aspectos demográficos y económicos, Granada, 1978.

- (coord.), Historia de Baeza, Historia, Literatura, Arte, Granada: Ayuntamiento de Baeza/Universidad de Granada, 1985.

- (coord.). Colección documental del Archivo Municipal de Úbeda, I, (siglo XIII), Granada: Universidad, 1990.

- (ed.). Colección documental del archivo municipal de Baeza (siglos XIII-XV), Jaén: Diputación, 2002.

Ruano, Francisco. Casa de Cabrera en Córdoba (1779, reed. Córdoba 1994).

Ruano Prieto, Fernando, "El condestable D. Ruy López Dávalos, primer duque de Arjona". Revista de Archivos, Bibliotecas y Museos, tomos VIII, IX y X, Madrid, (1903 y 1904).

Salazar y Acha, Jaime. "Los Osorio Un linaje de más de mil años al servicio de la Corona". Anales de la Real Academia Matritense de Heráldica y Genealogía, 4, (1996-1997), pp. 143-182.

- La casa del rey de Castilla y León en la Edad Media, Madrid: Centro de Estudios Políticos y Constitucionales, 2000.

Salazar y Castro, Luis de. Advertencias Históricas sobre las obras de algunos doctos escritores modernos... Madrid, 1688.

- Historia genealógica de la Casa de Lara, Madrid, 1696, 4 vols.

Segura Moreno, Manuel. Estudio del códice gótico (siglo XIII) de la catedral de Jaén, Jaén, 1976.

Suárez Fernández, Luis. "Auge y caída de un hombre nuevo: El condestable Ruy López Dávalos". Boletín de la Real Academia de la Historia, 195, cuad. 1, 1998, pp. 43-80.

Toral Peñaranda, Enrique, Úbeda (1442-1510), Jaén: Diputación, 1975.

Troyano Viedma, José Manuel. "La villa de Bedmar en la frontera de Mágina (10771466)". Sumuntán, 15 (2001), pp. 59-74.

Vázquez Campos, Braulio. Los adelantados mayores de La Frontera o Andalucía (siglos XIII-XIV). Sevilla, Diputación, 2006.

Villegas Díaz, Luis Rafael y García Serrano, Rafael, "Relación de los pueblos de Jaén ordenadas por Felipe II", Boletín del Instituto de Estudios Giennenses, 8889, pp. 9-304.

Viña Brito, Ana. "Don Pedro Girón y los orígenes del señorío de Osuna". Historia. Instituciones. Documentos, 17 (1990), pp. 267-285.

Ximena Jurado, M. Catálogo de los Obispos de las Iglesias Catedrales de Jaén y Anales Eclesiásticos de este Obispado. Ed. J. Rodríguez Molina y $\mathrm{M}^{\mathrm{a}} \mathrm{J}$. Osorio Pérez, Granada: Universidad, 1991. 